Please do not remove this page

RMIT

UNIVERSITY

\title{
Rheological characterisation of municipal sludge: A review
}

Eshtiaghi, Nicky; Markis, Flora; Yap, Shao; Baudez, Jean; Slatter, Paul

https://researchrepository.rmit.edu.au/esploro/outputs/9921859404901341/filesAndLinks?institution=61RMIT_INST\&index=null

Eshtiaghi, N., Markis, F., Yap, S., Baudez, J., \& Slatter, P. (2013). Rheological characterisation of municipal sludge: A review. Water Research, 47(15), 5493-5510. https://doi.org/10.1016/j.watres.2013.07.001

Document Version: Accepted Manuscript

Published Version: https://doi.org/10.1016/j.watres.2013.07.001

Repository homepage: https://researchrepository.rmit.edu.au

(c) 2013 Elsevier Ltd. All rights reserved.

Downloaded On 2023/04/27 01:33:03 +1000

Please do not remove this page 
Thank you for downloading this document from the RMIT Research Repository.

The RMIT Research Repository is an open access database showcasing the research outputs of RMIT University researchers.

RMIT Research Repository: http://researchbank.rmit.edu.au/

\section{Citation:}

Eshtiaghi, N, Markis, F, Yap, S, Baudez, J and Slatter, P 2013, 'Rheological characterisation of municipal sludge: A review', Water Research, pp. 1-18.

See this record in the RMIT Research Repository at:

http://researchbank.rmit.edu.au/view/rmit:22151

Version: Accepted Manuscript

Copyright Statement: (c) 2013 Elsevier Ltd. All rights reserved.

Link to Published Version:

http://dx.doi.org/10.1016/j.watres.2013.07.001

\section{PLEASE DO NOT REMOVE THIS PAGE}




\section{5}

\section{ABSTRACT}

864 Sustainable sludge management is becoming a major issue for waste water treatment plants 865 due to increasing urban populations and tightening environmental regulations for 866 conventional sludge disposal methods. To address this problem, a good understanding of 867 sludge behavior is vital to improve and optimize the current state of wastewater treatment 868 operations. This paper provides a review of the recent experimental works in order for 869 researchers to be able to develop a reliable characterization technique for measuring the 870 important properties of sludge such as viscosity, yield stress, thixotropy, and viscoelasticity 871 and to better understand the impact of solids concentrations, temperature, and water content 872 on these properties. In this context, choosing the appropriate rheological model and 873 rheometer is also important.

875 Keyword: Municipal Sludge, rheological models, yield stress, viscosity, thixotropy, 876 viscoelasticity, physico-chemical properties 


\section{Paper outlines:}

$878 \quad$ 1. Introduction

8792 2. Sludge rheology and Rheological models

880 3. Commonly used rheometers for sludge characterization

881 3.1. Capillary rheometer

882 3.1.1. End effect and wall slip

883 3.1.2. Overview of utilization of capillary rheometer for sludge characterization

884 3.2. Rotational rheometer

885 3.2.1. Gap size

886 3.2.2. Overview of utilization of rotational rheometer for sludge characterization

887 4. Viscosity

888 4.1. Effect of solids concentration on viscosity

889 4.2. Effect of temperature on viscosity

890 4.3. Effect of bound water content on viscosity

$891 \quad$ 5. Yield stress

892 5.1. Effect of solids concentration, water bound and temperature on yield stress

893 6. Thixotropy

894 7. Viscoelasticity

895 8. Relationship between sludge rheology and physico-chemical properties

8969. Conclusion

$897 \quad$ Acknowledgment

$898 \quad$ References 


\section{Introduction}

900 Internationally, wastewater treatment plants are striving to achieve a sustainable sludge 901 management strategy due to the legal banning of conventional sludge disposal methods 902 such as landfill. However, the rapid growth of urban populations has resulted in the 903 production of increasing volumes of sewage sludge. Existing municipal wastewater 904 facilities are reaching capacity, requiring expansion and upgrades to handle the additional 905 load that is anticipated in future. This means that a more concentrated and subsequently 906 rheologically complex sludge will be fed into sludge treatment plants (Eshtiaghi, et al., 907 2012a). Optimal and efficient design and operation of sludge treatment processes requires 908 accurate prediction of the hydrodynamic functioning of different equipment such as pumps, 909 heat exchangers and mixing systems. Prediction of the correct flow behaviour of these 910 engineering hydrodynamic processes requires accurate knowledge of the rheology of sludge

911 (Slatter, 2011, Ratkovich, et al., 2013; Esthtiaghi et.al. 2012a, Baroutian et al., 2013).

912 Slatter $(1997 ; 2001 ; 2003 ; 2004 ; 2008)$ has consistently shown that sludge rheology plays a

913 fundamentally important role in analysing the hydrodynamic behaviour of sludge, as it 914 flows through the treatment process. Therefore a better understanding of the flow properties 915 of sewage sludge is required in order to obtain useful parameters to improve the design of 916 sludge treatment processes and to ensure sustainable sludge management.

918 Recently, Ratkovick et al. (2013) presented the importance of activated sludge rheology on 919 pumping, mixing, bubble diameter, secondary settler hydrodynamic, etc. In particular 920 Ratkovick et al. (2013) focused on the viscosity of activated sludge and compared the 
921 viscosity data published from different experimental set ups; this highlighted how changes

922 in experimental protocol would give different results and finding an absolute value for

923 viscosity is not possible. In the second part of this paper, Ratkovich et al. (2013) explains

924 the correct procedure for modelling experimental data in order to obtain a reliable result.

926 In this paper, we describe a general overview of the different rheological properties of 927 wastewater municipal sludge such as viscosity, yield stress, thixotropy, and viscoelasticity 928 as well as the commonly used rheometers.

929

930 2. Sludge rheology and rheological models

931 Rheology is the science that studies the deformation and flow of matter. Dilute sewage 932 sludge behaves closely to a Newtonian fluid (Sanin, 2002) however, at higher solids 933 concentrations (3-10\%) the behavior becomes non-Newtonian and for which the 934 rheological characteristics are highly dependent on the treatment process (Lotito et al., 935 1997; Battistoni, 1997).

Figure 1: Rheological models (Linear axes)

937 The non-Newtonian rheological models more commonly used to describe sludge behavior 938 in steady state laminar flow are the simple power-law or Ostwald model (Eq. 1) (Kurath 939 and Larson, 1990; Moeller and Torres, 1997; Bougrier et al., 2006; Terashima et al., 2009;

940 Wu et al., 2011), the Bingham model (Eq. 2) (Sozanski et al., 1997; Guibaud et al., 2004, $941 \mathrm{Mu}$ and Yu, 2006), the Sisko model (Eq. 3) (Mori et al., 2006; Pollice et al., 2007), the 942 Herschel-Bulkley model (Eq. 4) (Slatter, 1997; Baudez, 2001), the Casson models (Eq.5) 
943 (Chhabra and Richardson, 2008), the truncated power-law (Eq.6) (Baudez, 2008; Eshtiaghi

944 et al., 2012b) and the Cross viscosity fluid model (Eq.7) (Sybilski, 2011; Eshtiaghi et al., 945 2012b)

$946 \tau=K \dot{\gamma}^{m}$

Eq. 1

$947 \tau=\tau_{o}+\eta \dot{\gamma}$

Eq. 2

$948 \tau=\eta_{\infty} \dot{\gamma}+K \dot{\gamma}^{m}$

Eq. 3

$949 \tau=\tau_{o}+K \dot{\gamma}^{m}$

Eq. 4

$950 \tau=\sqrt{\tau_{c y}}+\sqrt{\eta_{c} \gamma^{2}}$

Eq. 5

$951 \quad \frac{\tau}{\tau_{C}}=\left(\frac{\dot{\gamma}}{\dot{\gamma}_{C}}\right)^{n}$

Eq. 6

$952 \quad \mu=\frac{\mu_{0}}{1+K \dot{\gamma}^{m}}$

Eq. 7

953

954 Depending on the presence of a yield stress, the power law (or Ostwald model) (Eq. 1) and 955 Bingham are the most basic and common rheological models,

956

957 The Herschel-Bulkey fluid model is a general form of Bingham model; it is modified to

958 embrace the non-linear flow curve. The Herschel-Bulkley model describes sludge as a 959 shear thinning material and is most commonly used to characterize concentrated sludge 960 (Baudez and Coussot, 2001; Baudez et al, 2011).

961 
962 Recently, Khalili Garakani et al. (2011) utilized different types of rheological models to

963 characterize activated sludge in a submerged type membrane bioreactor and used the

964 Herschel-Bulkley model to describe the behavior of activated sludge at high concentrations,

965 and the Bingham model to characterize dilute sludge. Also, they used the power law model

966 to describe the viscosity of sludge in the low shear range.

968 Martin et al. (2011) further commented that the Bingham model is suitable for

969 characterization of membrane bioreactor and anaerobic digested sludge at intermediate to

970 high shear range.

971

972 The power law model fails at modeling the Non-Newtonian fluid behavior at high shear

973 rate where viscosity ultimately remains higher than water viscosity. This failure can be

974 rectified by using Baudez's model (2011) in which the Herschel-Bulkley and Bingham

975 models are coupled (Eq.8) to represent the behavior of sludge over the full range of shear

976 rates, where the apparent viscosity tends to a limiting value i.e. plateau:

$977 \tau=\tau_{o}+\left(K \dot{\gamma}^{m-1}+\alpha_{0}\right) \dot{\gamma}$

Eq. 8

978

979 where $\alpha_{0}$ is a plateau viscosity of sludge, describing the rheological behavior of sludge at 980 high shear rates.

981 Several researchers have attempted to correlate both ' $m$ ' and ' $K$ ' with solids concentrations 982 of sludge. For ' $K$ ', the relationship had been described with a simplified correlation 
983 proposed by Landel et al. (1965) (Eq. 9) or exponential function (Eq. 10) (Mori et al., 2006;

984 Moreau et al., 2009) and regression analysis (Eq.11, Eq.12) by Lotito et al. (1997) and 985 Allen and Robinson (1990), respectively:

$986 K=\eta_{w}\left(1-\frac{T S S}{T S S_{\max }}\right)^{-m}$

$987 \quad K=a \exp (b \times[T S S])$

988 Where subscript $w$ refers to water, $a$ and $b$ are empirical coefficients.

$989 K=(a . T S S+b) \cdot T S S+c$ Eq.11

$990 K=a \cdot T S S^{b}$

991 Where $a_{s} b$ and $c$ are correlation coefficients.

992

993 On the other hand, ' $m$ ' can be correlated to the total suspended solids with either a 994 polynomial (Eq. 13) (Slatter, 1997), linear (Eq. 14) (Mori et al., 2006), power-law function 995 (Eq. 15) (Moreau et al., 2009) or regression analysis (Eq.16, and Eq.17) (Lotito et al. 1997 996 and Allen and Robinson, 1990, respectively):

997

$998 m=b_{1} T S S^{2}+b_{2} T S S+1$

Eq. 13

$999 m=a-(b \times[T S S])$

Eq. 14

$1000 m=a-\left(b \times[T S S]^{c}\right)$

Eq. 15

$1001 m=($ a.TSS $+b), T S S+c$

Eq .16

$1002 m=a \cdot T^{2} S^{b}$

Eq .17 
1003 where TSS is total solids concentration $(\mathrm{g} / \mathrm{L})$ with a, $b$ and $c$ as the empirical coefficients.

1004 The flow behavior index and flow consistency coefficient may not be readily used for

1005 rheological characterization of sludge, but have proved to be useful indicators of the sludge

1006 behavior during rheological measurement.

1008 However, Baudez et al. (2011) revealed similarities in the rheological behavior of anaerobic

1009 digested sludge at different solids concentrations by developing a master curve on which

1010 each single curve can be plotted. This means that the power-law index remains constant

1011 over a wide range of solids concentration. These results were also obtained for highly

1012 concentrated sludge from several origins (Baudez et al., 2006), pointing out that rheological

1013 parameters are only dependent of two characteristics, the yield stress and high shear

1014 viscosity.

1015

1016 Based on a review paper by Seyssiecq et al. (2003), the choice of rheological model is

1017 shown to be subjective and highly dependent on the experimental condition such as applied

1018 shear stress or sheear rate range as well as type of sludge. For concentrated suspensions, the

1019 Ostwald or Bingham model, in general, were the most common model used to describe the

1020 rheological behaviour of sludge. Baudez (2002) found that the behaviour of pasty sewage

1021 sludge is highly dependent on hydrodynamic and particle interactions. This is due to the

1022 competition between these two interactions when sludge is sheared; particle interactions

1023 induce structure build-up (aging) whilst hydrodynamic forces tend to resist particle

1024 interactions and keep the structure in a broken state (rejuvenation). Baudez (2008) also

1025 introduced a new technique to measure the dual rheological behavior of sludge using 
1026 reconstruction of instantaneous velocity profiles based on repetitive creep measurements.

1027 He revealed that the sludge will only achieve homogenous flow (following a truncated

1028 power-model) once the shear rate and shear stress are higher than a critical value. As the

1029 critical shear rate and shear stress are highly dependent on solids content, this implies that

1030 thixotropy may be significant for thickened sludge.

1031

1032 The rheological data available in literature are rarely comparable as there is no standard

1033 protocol for characterizing the rheology of sludge. Sample handling and storage prior to

1034 characterization have a significant impact on the rheology of sludge. Furthermore, time

1035 dependent, thixotropic properties have eluded measurement accuracy. Therefore, there is a

1036 necessity for developing a standard protocol to characterize the rheological behavior of

1037 sludge so that consistent data can be reported in literature for comparison.

1038 3. Commonly used rheometers for sludge characterization

1039 The instrument used to measure the flow curve of sludge is known as a rheometer. At

1040 present, among the commercial available rheometers, rotational and capillary have been

1041 used for sludge applications. The test for sludge is carried out over a range of shear stresses

1042 or shear rates that are mostly encountered in practice at steady state flow. The rheological

1043 information on sludge in laminar region is often extrapolated by several orders of

1044 magnitude to predict the behavior of sludge at high shear region (turbulent regime).

1045 Therefore, the accuracy of measurement is of utmost important. 
1047 The papers reviewed in this work showed that the rotational viscometer, particularly 1048 concentric cylinder, has been involved in a wide range of sludge charaterisation work for

1049 various industrial applications. In the past, most research focused mainly on identifying the 1050 appropriate geometry for sludge measurement and the error associated with such 1051 measurement (Seyssiecq, Ferrasse et al., 2003). In the activated sludge process, the 1052 secondary clarifier is recognised as the main bottleneck and fulfils a triple-role as a 1053 clarifier, sludge thickener and sludge storage zone (Weiss et al., 2007). Therefore, most 1054 researchers have tended to sample sludge from the secondary clarifier for rheological study.

1055 They were utilising the rotational viscometer for the rheological study of the activated 1056 sludge process to develop a more effective and sustainable sludge treatment system. Also, 1057 rotational rheometers have been used widely for characterization of membrane bioreactor 1058 sludge in order to improve the conventional activated sludge treatment process. Most of the 1059 reseachers reported using either Brookfield or Haake type rotational rheometers with 1060 similar model or geometries to characterise their research works. Despite the fact that 1061 similar rheometers have been used, the results are not comparable. Ratcovich et al. (2013) 1062 has presented an overview on the problems associated with comparing activated sludge 1063 rheological data due to the lack of measurement protocol data.

1065 This problem is further complicated by variations of sludge samples and its physico1066 chemistry used among the reseachers and the time-dependent properties of sludge. This 1067 makes it difficult to identify whether discrepancies in results are due to the thixotropic 1068 property of sludge, the origin of sludge or the artefacts of the measuring process and 1069 equipment. Because, measurement errors associated with different inner cylinder design has 
1070 not been examined properly. Although these designs are said to overcome the wall or end

1071 effects during the measurement. Therefore, it is important to examine the physical

1072 properties of sludge as well as identifying the major biological components or the

1073 associated interparticle interactions that are responsible for its rheological behaviour. This

1074 information will be useful for developing models to quantify wall and end effects

1075 associated with rotational rheometer and enchance the measurement reliability in 1076 rheological study for sludge.

1077

1078 In the following section, an overview of the utilization of capillary and rotational

1079 rheometers with their brand and geometry used for sludge characterization is presented.

1080 Table 1 in supplementary provides a summary of research works utilized rotational 1081 rheometers.

\section{$1082 \quad$ 3.1. Capillary rheometer}

1083 The capillary or tube viscometer, also known as Ostwald viscometer, employs a pressure 1084 gradient to cause fluid to flow in laminar region at a measured shear rate through a capillary 1085 tube of known diameter and length (Figure 2). It is the most common instrument for the 1086 fluid viscosity measurement due to its relative simplicity, low cost and accuracy (in the 1087 case of long capillaries) (Chhabra and Richardson, 2008). Slatter (1997) and recently 1088 Ratcovich et al. (2013) has reviewed the advantages and disadvantages of using capillary 1089 viscometer for sludge characterization. The principal advantages are mechanically simple 1090 (similar geometry to pipe flow), high shear ranges can be attained and enable measurement 1091 of diameter dependent effect. On the other hand, the disadvantages include larger sample 
1092 volumes required, the same sample of fluid cannot be subjected to sustained shear for

1093 measuring time-dependent effects and the sample is subjected to a varying rate of shear

1094 over the tube cross section. Chhabra and Richardson (2008) added that cleaning could also

1095 be a problem due to the small diameter of the tube.

1096

Figure 2.Schematic of capillary rheometer (image courtesy to google)

1097 3.1.1. End effect and wall slip

1098 The two common sources of error associated with capillary devices are so called end effects

1099 and wall effects. For purely viscous fluid, this effect is usually neglected as long as the

1100 length to diameter ratio (L/D) of the capillary tube is of the order of 100 to 120 (Nguyen et

1101 al., 2007a). As for viscoelastic substances larger L/D values are required and as of now

1102 there is no conclusive estimate of the desired ratio (Nguyen, et al., 2007a). On the other

1103 hand, wall slip mechanism, which is commonly accepted for a concentrated suspension, can

1104 be explained by formation of a slip layer adjacent to the wall due to particle migration

1105 (Baudez et al., 2007; Nguyen et al., 2007b). The slip phenomenon has been well

1106 documented by others (Rosenberger et al., 2002; Bellon et al., 2007; Paredes et al., 2011).

1107 3.1.2. Overview of utilization of capillary rheometer for sludge

\section{8 characterization}

1109 One of the earliest attempts to study the rheological properties of sewage sludges using

1110 capilliary rheometers was done by Babbit and Caldwell (1939). However, their results were

1111 not satisfacory due to the difficulties faced during the measurement. These include

1112 insufficicent sludge sample, clogging and velocity control by means of a valve. Notable

1113 contributions from other reseachers in this area include Brisbin (1957) using a capillary 
1114 rheometer to correlate the rheological properties sludge with solids concentration, by

1115 Sirman (1960) to characterize digested sludge. Bhattacharya (1981) realized the

1116 significance of the physico-chemical effect on the sludge rheological properities and

1117 utilized a tube viscometer to examine the effect of temperature and solids concentration on

1118 the sludge behaviours. Seyssiecq, et al. (2003) have acknowledged some of the works done

1119 on sludge characterization using a commercially available capillary rheometer in their

1120 review paper, notably anaerobic digested sludge (Behn, 1962) and concentrated sludge

1121 (Gasnier, et al., 1986; Hiemenz and Rajagopalan, 1997). Most recently, the capillary

1122 rheometer was used by Grant and Robinson (1990) to measure the rheological properties of

1123 filamentous broth, by Slatter (1997) to relate rheological properties of sludge to operating

1124 conditions in the sludge pumping process and also by Poitou, et al. (1997) to study the

1125 rheological and mechanical properties of pasty sludge.

1126

1127 Bache and Papavasilopoulos (2000) employed Ostwald rheometer in their research to

1128 analyze the viscosity of sludge in response of polymer conditioning and determine the

1129 optimum polymer dosage required for dewatering applications. Ward and Burd (2004) used

1130 modified Ostwald rheometer to perform viscosity measurements on conditioned sludge

1131 with different $\mathrm{pHs}$ and solids concentrations at $100^{\circ} \mathrm{C}$.

1132

1133 A recent article by Pullum et al. (2010) questioned the validity of tube viscometer in

1134 examining the rheological properties of stable 'homogeneous' suspension with coarse

1135 particles. The experiment was carried out with CMC solution and glass beads $(\sim 1 \mathrm{~mm})$ as

1136 pure carrier fluid and coarse particle, respectively, in small and industralized pipes. Their 
1137 result showed that the stratified bed flow effect in homogeneous suspension may be

1138 negligible in tube capillary, but it dominated the transport pressure gradients in the

1139 industralized pipe. Their work has also cast doubts upon the validity of capillary tube data

1140 obtained with 'normal' slurry size distribution and whether it can be used directly in system

1141 design and process control for industrial scale. Clearly this phenomenon will also need to

1142 be studied to examine the validity of tube viscometer data for the rheological

1143 characterisation of primary sludge, if the design of high concentration pumping systems for

1144 primary sludge is to be performed with any certainty.

1146 The most recent development of capillary rheometer technology in sludge application was

1147 presented in an article in which Slatter et al. (1996) described a modified capillary device

1148 called the Balanced Beam Tube Viscometer (BBTV). The device is composed of a 1149 transparent tube of various diameters that connects to two pressure vessels located at the 1150 either end of the beam. Compressed air with known pressure enables sludge to flow 1151 through the tube at a controlled rate. Mass in the load cell is registered over time, indicating 1152 the flow transferred through the tube. The principal advantage of this device is that sludge

1153 flow is not measured with a classical flow meter but calculated from the variations in mass

1154 measured by simple weighing. Therefore the accuracy is higher than that of a conventional

1155 flow meter and very low flow rates can be measured, which overcame the earlier velocity 1156 control issue by valve as depicted by Bobbit and Calldwell (1936). Slatter et al. (1998) 1157 improved the BBTV design to facilitate more accurate design of pipe and pumping plants 1158 for non-Newtonian slurries. This improvement allowed large number of data points to be 1159 collected in laminar and turbulent region and its transition point to provide useful data for 
1160 process design which cannot be done with conventional capillary tube viscometer.

1161 However, the current design of BBTV is limited by maximum pipe diameter of $50 \mathrm{~mm}$ and

1162 still had not overcome the limitations of the previous design, such as inability to measure

1163 time dependency of materials and large sample volume is required. Nevertheless, their

1164 work was able to demonstrate that BBTV is a versatile and reliable instrument for both

1165 routine analyses and research work and can achieve more accurate measurement compared

1166 to typical tube viscometer. Most importantly, it has also demonstrated the potential to be

1167 adapted to enhance the accuracy and reliability for rheological measurement of activated

1168 sludge.

1169

$1170 \quad 3.2$. Rotational rheometer

1171 The rotational rheometer with concentric cylinder geometry has became widely accepted

1172 and commercially available in recent years, and the most common class of rheometer used

1173 in sludge rheology (Figure 3). This device relates the measured torque to shear stress as

1174 well as angular velocity to shear rate, therefore enables evaluation of the rheological

1175 properties of sludge. Detailed theoretical analysis to develop basic equations for rotational

1176 viscometry is available in standard texts such as that by Van Wazer (1963).

1177 Figure 3.Schematic of rotational rheometer with different geometry such as a) vane, 1178 b) concentric, c) cone-plate, d) parallel plate, e) double concentric (image courtesy to 1179 google)

1182 The design of this rheometer offers unique features to study the rheological property of 1183 sludge, which is not available in other types of rheometer. These advantages include 
1184 continuous operation to allow evaluation of time dependent properties, small sludge 1185 samples for testing, can be installed as bench top instrument and enables rheograms to be 1186 obtained when directly linked to a PC (Dick and Ewing, 1967; Slatter, 1997, Ratkovich et 1187 al., 2013).

\subsubsection{Gap size}

1190 Dick and Ewing (1967) and Dick and Buck (1985) have provided a comprehensive

1191 equipment analysis and requirement for sludge application. Dick and Ewing (1967) noted

1192 that narrow gap rotational rheometer was not suitable for rheological measurement of

1193 sludge since the gap size was much smaller compared to the particle size in the suspension

1194 being investigated. They have commented that the gap size must be at least 10 times larger

1195 than particles in the sludge to ensure the device was sensitive enough to measure low

1196 viscosity substance. On the other hand, a wide gap would contribute to the development of

1197 turbulence which lead formation of strong centrifuge action within the measuring gap.

1198 Centrifuge action can cause the readings to decay with time and subsequently lead to

1199 erroneous identification of time-dependent property or thixotropy (Slatter, 1997). To

1200 minimize the effect due to centrifuge action, Chhabra and Richardson (2008) suggested that

1201 the ratio of diameter of inner to outer cylinder must be larger than 0.99. Seyssiecq, et al.

1202 (2003) has discussed this issue in his review paper and noted that the choice of concentric

1203 cylinder geometry depended on the type of sludge that one is working with. Indeed, the

1204 effect of measuring geometries on sludge rheology has been demonstrated by Mori et al.

1205 (2006). In their experiments, a rotational and controlled stress rheometer with concentric 
1206 cylinder (CC) (measuring gap: 1mm) and double concentric cylinder (DCC) (measuring 1207 gap: 0.38 and $0.42 \mathrm{~mm}$ ) were used to obtain the flow curves for activated sludge, which 1208 was composed mainly of macroflocs with mean diameter of $125 \mu \mathrm{m}$. The experimental 1209 results indicate that the CC systems is suitable for characterization of sludge whereas the 1210 dimension of the DCC geometry are too small leading to blockage of flow as the 1211 suspension is sheared.

\section{3.2.2. Overview of utilization of the rotational rheometer for sludge}

\section{3 characterization}

1214 The Rotational viscometer has proven to be a useful tool to obtain rheological properties of 1215 sludge for process design and modelling as well as optimization. Most of reseachers 1216 employed this type of rheometer to examine the influence of operating conditions and 1217 physico-chemical properties on the viscosity of sewage sludge (summary presented in the 1218 Table 1 as a supplimantry material).

1220 Several authors used a stress-controlled concentric cyclinder rheometer - DSR200 to

1221 evaluate rheological properties of anaerobic digested sludge at various solids concentrations 1222 (Esthiaghi, et al. 2012b) and temperature (Baudez et al., 2013b). The effect of measuring 1223 geometries on the rheological behaviour of sludge was reviewed by Seyssiecq et al. (2003), 1224 Mori et al. (2008) and by Mori et al. (2006) using different concentric cylinder geometries. 1225 Laera et al. (2007) and Pollice et al. (2007) as well as Pollice et al. (2008) have employed 1226 Rheotest 2.1, Haake Mendigen (GMBH) equipped with concentric cylinder to examine the 1227 rheology of bioreactor sludge at solids retentions times of 20 days at $20^{\circ} \mathrm{C}$. Several 
1228 researchers employed rotational rheometer in examining the effect of pre-treatment and 1229 polymer conditioning prior dewatering on the rheology of sludge. In the recent years, 1230 influence of ultrasonification pretreatment on the rhelogical features of sludge has been 1231 widely studied with different types of rotational rheometer such as Brookfield type 1232 rotational rheometer (Pham et al., 2009; Pham et al., 2010) and RS 300 stress-controlled 1233 rheometer (Ruiz-Hernando et al., 2010). Kim et al. (2009) used a Brookfield type to 1234 investigate the rheology of secondary sludge after alkaline pretreatment and hydrogen 1235 peroxide oxidation to investigate the efficiency of each process for more effective excess 1236 sludge reduction. Jolis (2008) and Verma et al. (2007a) utilized rotational disk rheometer 1237 and Brookfield type rheometer, respectively, to demonstrate that solids after thermal 1238 hydrolysis pretreament, sludgeviscosity reduces and the fraction of soluble organic matter 1239 increases. Ayol and Dentel (2005), on the other hand, analysed the rheology of anaerobic 1240 digested sludge after enzymatic treatment with a Brookfield type rheometer to derive 1241 parameters that may be used to characterise drainability and filterability dynamic.

1243 The Rotational rheometer is also commonly used for rheological characterisation of sludge 1244 samples obtained from different stages or processes in sludge treatment. Mu and Yu (2006) 1245 used a shear controlled rotational rheometer to determine the characteristic of granular 1246 sludge with average size of 150 to $250 \mu \mathrm{m}$ in an upflow anaerobic reactor. Mu and Wang 1247 (2007) utilized a rotational rheometer equipped with double gap measuring system to 1248 determine surface characteristic of anaerobic granular sludge in acidgenic fermentative 1249 process. Fonts et al. (2009) employed a rotational rheometer for viscosity measurment as 1250 part of their works to evaluate the physico-chemical properties of pyrolysis liquid of 
1251 sewage sludges for possible energy applications. Wang and Dentel (2011) used Brookfield 1252 rheometer equipped with ultralow adapter to determine the supernatant viscosity of raw 1253 anaerobic digested sludge after centrifuge. This type of viscometer was also used to 1254 characterise sewage sludge and wastewater that were incubated with different types of 1255 fermenter. For instance, Verma, Brar et al. utilized a Brookfield type viscometer to 1256 characterise Trichoderma viride fermented starch wastewater (2006) and activated sludge 1257 (2007b) as well as Bacillus Thuringiesis fermented primary secondary and mixed sludge 1258 (60\% primary, 40\% secondary) (Brar, Verma et al., 2005; Brar, Verma et al., 2008) to 1259 evaluate the optimum operating condition and to test their feasibility as potential growth 1260 substance on the basis of process performance and rheology when compare to other 1261 commercial medias. Recently, Seviour et al. (2009a) employed a strained controlled 1262 rheometer ARES with parallel plate to characterise aerobic sludge of a lab-scale sequencing 1263 batch reactor at different $\mathrm{pH}$, temperature and salt concentration based on storage modulus $1264\left(G^{\prime}\right)$ and loss modulus $\left(G^{\prime \prime}\right)$ to demonstrate that the granules were hydrogels. Khongnakorn 1265 et al. (2010) demonstrated that they were able to utilize a stress controlled Haake rheometer 1266 to evaluate the rheological properties of membrane bioreactor sludge during unsteady state 1267 flow condition at $21^{\circ} \mathrm{C}$. The experiment showed that change in applied stress could affect 1268 the solubility of organic materials in sludge and therefore influence the solids behaviour of 1269 sludge. Their work had highlighted the possibility to improve the performance of 1270 membrane bioreactor unit by modifying the presense of soluble microbial compounds i.e. 1271 the microbial activity induced by the fermenter. 
1273 The Rotational rheometer can also be used to analyse dewaterability of sludge through 1274 rheological study. Hou and $\mathrm{Li}$ (2003) used a Brookfield rheometer to evaluate the

1275 feasibility of using rheological properties to assess dewaterbility of inorganic water and 1276 organic activated sludge that were conditioned with fly ash and polymer. They have 1277 concluded that both minimum viscosity and rheograms peaks could be used to measure the 1278 dewaterability of inorganic water sludge, but not for organic sludge. Örmeci and Abu-Orf 1279 (2005) proposed a protocol to directly measure the overall network strength of sludge using 1280 concentric cylinder rheometers to evaluate the dewaterability of wastewater sludge. Indeed, 1281 Örmeci (2007) has also reported the problem associated with the reproducibility of the 1282 measurement using concentric cylinder due to difficulties to obtain representative sub1283 samples from well flocculated sludge in his work to optimize conditioning and dewatering 1284 process in wastewater treatment.

1286 Several researchers employed this type of rheometer to determine characteristic of sludge in 1287 menbrane bioreactor to evaluate the process performance and optimization. Chu, Wu et al. 1288 (2007) used a shear rate-controlled Brookfield viscometer to test the dewaterability and 1289 perform structural analysis on the sludge sampled from a pilot-scale membrane bioreactor 1290 and estimated the appropriate polymer dose prior dewatering to improve the process 1291 performance via hystersis loop test. Van Kaam et al. (2008) used a Bohlin C-VOR 200 1292 Rheometer to perform viscosity and oscillation measurement of mixed liquor. Ho and Sung 1293 (2009) used a Haake type viscometer to investigate the effect of solids concents and 1294 hydrodynamic conditions on microfiltratio (pore size $=1 \mu \mathrm{m}$ ) of anaerobic digested sludge. 1295 Recently, Brannock et al. (2010) utilized a rotational stress-controlled Haake rheometer to 
1296 investigate mixing characteristic of full-scale membrane bioreactors and developed a 1297 computational fluid dynamics model framework for biological wastewater treatment which 1298 accounted for aerations, sludge rheology and geometries of the reactor itself. The validity 1299 of model has been verified with two full-scale membrane bioreactors and successfully

1300 predicted the overall reactor residence time distribution with high precision. Weiss et al. 1301 (2007) used a rotational viscometer to perform on-site rheology experiments to develop a 1302 computational fluid dynamic model that predicted the sedimentation of activated sludge in 1303 a full scale flat bottom circular secondary clarifier that is equipped with a suction-lift sludge 1304 removal system. The model prediction was showed to agree well with the measured sludge 1305 concentration profiles in the clarifier for two different treatment plant loadings.

1306 Efterkharzadeh et al. (2007) have employed a Haake type rheometer to obtain site-specific 1307 sludge rheology data to upgrade the wastewater treatment system to handle higher solids 1308 concentrations. The rheology data were used to prepare a scale-up model for the digester 1309 mixing system as well as develop a computational fluid dynamics model that can be used to 1310 assess the effectiveness of mixing. The paper demonstrated the benefits of analysing site1311 specific sludge rheology for assessing the effect of solids concentration on the mixing 1312 efficiency of anaerobic digester.

\section{4. Viscosity}

1315 Viscosity is defined as the ratio of shear stress to shear rate, which can be evaluated by 1316 means of the flow curve. The more viscous and less flowable the fluid, the greater is the

1317 viscosity (Ratkovich et al., 2013). This parameter has been a fundamental measure for 
1318 physical characteristic of sludge suspension relating to deformation and flow properties.

1319 Since sludge is non-Newtonian fluid as the viscosity changes with shear rate or applied

1320 stress. Therefore, the term 'apparent viscosity' is used to describe this behavior. A non-

1321 Newtonian behavior of sludge observed to be shear-thinning (Chaari et al., 2003), is

1322 commonly characterized by a decreasing apparent viscosity over increasing shear rate, but

1323 at extreme low and high shears rate exhibit Newtonian behavior. The resulting apparent

1324 viscosities at low and high shear rate are known as zero shear viscosity, $\eta_{0}$, and infinite

1325 shear viscosity, $\eta_{\infty}$, respectively. Thus it is also valid to say that the apparent viscosity of

1326 shear thinning fluid reduces from zero shear viscosity to infinite shear viscosity with

1327 increasing shear rate.

1329 Several researchers chose to characterize sludge rheology based on limiting viscosity

1330 (Tixier et al., 2003a; Pevere et al., 2006). Due to non-Newtonian behavior of sludge, the

1331 rheological property of sludge can be better described by a single parameter of limiting

1332 viscosity (Seyssiecq et al., 2003), which allows proper comparison of viscosity for different

1333 sludge samples (Tixier et al., 2003a). Limit viscosity corresponds to an asymptote value of

1334 the viscosity-time curve at high shear rate when the apparent viscosity becomes almost

1335 constant. It can be interpreted as being the viscosity of sludge corresponding to the

1336 maximum dispersion of floc under the influence of shear rate (Tixier et al., 2003b). This

1337 parameter has been employed to characterize a wide range of sewage sludge, such as

1338 anaerobic digested sludge (Battistoni et al., 1993; Pevere et al., 2006; Pevere et al., 2007; Li

1339 and Yu, 2011), aerobic sludge (Riley and Forster, 2001; Tixier et al., 2003b; Su and Yu, 
1340 2005), bioreactor sludge (Abu-Jdayil, Banat et al., 2010) and activated sludge (Tixier et al.,

1341 2003a). Besides characterizing sludge, limit viscosity serves as a good indicator of internal

1342 resistance (Battistoni et al., 1993) of different origins (Tixierb et al. 2003a,b) for the same

1343 treatment process. Several researchers have also attempted to use viscosity as means to

1344 evaluate thixotropic properties of sludge (Baudez and Coussot, 2001; Brar et al., 2005).

1346 4.1. Effect of solids concentration on viscosity

1347 For a suspension that is diluted enough and remains Newtonian, the relationship between

1348 viscosity and particle concentration can be described by the Einstein equation:

$1350 \quad \eta=\eta_{0}(1+2.5 \phi)$

Eq. 18

1351 where $\eta$ is viscosity, $\eta_{0}$ is the viscosity of the fluid phase and $\phi$ is the particle volume

1352 fraction. The equation assumes the solids suspended in the fluid are spherical, non1353 interacting, insoluble and rigid (Sanin, 2002).

1355 The effect of solids content on the limit viscosity of sludge has been examined in a great 1356 number of studies. It was found that the limit viscosity of sludge increases with solids 1357 content (Forster, 2002; Tixier et al., 2003b; Pevere et al., 2006; Mu et al., 2007; Moreau et 1358 al., 2009; Abu-Jdayil et al., 2010). At high solids content, structural units of suspension 1359 may be larger in size and closer to each other, leading to stronger inter-particle interactions 1360 and hence the higher apparent viscosity of sludge. This behavior has been mostly described 1361 with an exponential function (Battistoni et al., 1993; Rosenberger et al., 2002; Tixier et al., 
1362 2003b; Pevere et al., 2006; Abu-Jdayil et al., 2010) or power model (Lotito et al. 1997;

1363 Tixier et al. 2003b; Su and Yu, 2005). Recently, Baudez et al. (2011) demonstrated that the

1364 relationship between Bingham viscosity and solids concentration followed an exponential

1365 law, too. Considering most sludge has high fraction of suspension and interact with each

1366 other, it is unrealistic to expect that Einstein law is to be applied to these systems (Sanin,

1367 2002). The effect of solids concentration on viscosity of sludge is in parallel with particle

1368 sizes, as both attribute to an increase of inter-particle interactions. As shown by Pevere et

1369 al. (2006), decrease in particle size at a constant solids concentration increased limit

1370 viscosity of sludge. This suggested that a decrease in particle size increases the surface area

1371 of particle to interact with each other. This also underlines the importance of the particle-

1372 particle interactions from a quantitative point of view (Pevere et al., 2006).

1374 Recently, Khalili Garakani et al. (2011) have proposed a simplified correlation (Eq.19) to 1375 relate viscosity of activated sludge with mixed liquor suspended solids $\left(\phi_{p}\right)$ and shear rate $1376(\dot{\gamma})$ at $20^{\circ} \mathrm{C}$.

$1377 \quad \eta=a \times\left(\frac{\phi_{p}{ }^{b}}{\dot{\gamma}}\right)$

Eq. 19

1379 where $a$ and $b$ are the empirical coefficient.

1381 This correlation has been verified with the experimental data presented in work of 1382 Rosenberger et al. (2002) and Yang et al. (2009) and showed a better prediction capability, 
1383 especially at lower and upper Newtonian regions. The authors also related the aeration

1384 intensity $\left(U_{g}\right)$ to the viscosity of sludge based on the work of Popovic and Robinson (1984)

1385 and yields the following equation, which reveals the significance of air injection in an

1386 aerated fermenter:

1387

$1388 \eta \eta=\frac{a}{c} \times\left(\frac{\phi_{p}{ }^{b}}{U_{g}}\right)$

Eq. 20

1390 where $a$ and $c$ are the empirical coefficient.

1392 Furthermore, they have emphasized the use of more sophisticated viscosity models such as

1393 Carreau or Cross model as they are able to provide the best prediction of viscosity in the 1394 whole wide range of shear rates for activated sludge. Saffarian et al. (2011) have applied 1395 modified Bingham model, based on the work of Papanastasiou (1987), to simulate the 1396 sludge flow of a secondary clarifier in a sewage treatment, in which the plastic viscosity $1397\left(\eta_{p}\right)$ can be expressed as below:

$1399 \quad \eta_{p}=[1-\exp (-m \dot{\gamma})]^{n} \tau_{B} \dot{\gamma}+\eta_{B}$ Eq. 21

1401 where $m$ and $n$ are shear rate and growth power rate, respectively, and $\tau_{B}$ and $\eta_{B}$ are 1402 Bingham yield stress and viscosity, respectively, and are expressed as a function of 
1403 temperature and concentration in the literature. The correlation has been verified and fitted

1404 well with the experimental data by Weiss et al. (2007).

1405

1406 Krieger - Doughety (1959) Viscosity model that takes into account the maximum packing

1407 fraction $\left(\phi_{m}\right)$, intrinsic viscsoity $(\eta)$, and volume fraction of dispersed phase $(\phi)$ which

1408 modified by various authors ( Behzadfar et al. (2009) and Kitano et al. (1981)) has been

1409 presented in Eq.22.

$1410 \eta_{r}=\left(1-\frac{\phi}{\phi_{m}}\right)^{-[\eta] \phi_{m}}$

1412 4.2. Effect of temperature on viscosity

1413 The temperature dependent properties of sludge have been well-documented and examined.

1414 It is agreed in general that increase in temperature will result in a decrease in sludge

1415 viscosity (Battistoni et al. 1993; Sozanski et al., 1997; Mu et al., 2007; Abu-Jdayil et al.,

1416 2010; Baudez et al., 2013b). However, the temperature effect is not significant if the

1417 temperature range examined is approximately room temperature or even lower (Moreau et

1418 al., 2009). The relationship of sludge viscosity and temperature can be described with an

1419 Arrhenius type equation (Eq.23):

1420

$1421 \quad \eta_{\infty}=K \exp \left(\frac{E_{a}}{R T}\right)$ 
1423 where $\eta_{\infty}$ is limit viscosity, $K$ is empirical constant, $T$ is absolute temperature, $R$ is

1424 universal gas constant, and $E_{a}$ is the activation energy. This expression has been used to

1425 describe temperature effect on limiting viscosity of several types of sludge: bioreactor

1426 sludge (Yang et al., 2009; Abu-Jdayil et al., 2010), anaerobic digested sludge (Battistoni et

1427 al., 1993; Mu et al., 2007; Pevere et al., 2009; Baudez et al., 2013b) and diluted sludge

1428 (Sozanski et al., 1997). Several researchers have utilized different form of equations to

1429 estimate the temperature effect on viscosity of sludge. Sozanski et al. (1997) studied the

1430 effect of temperature on the Bingham plastic viscosity and yield stress. The relationship

1431 between temperature and rheological parameters was defined using a temperature factor

1432 "WT":

1433

$1434 \quad(W T)_{1}=\frac{1}{T-273,45}\left[\frac{\left(\eta_{B}\right)_{27 E .45}}{\left(\eta_{B}\right)_{T}}-1\right] \cdot 100$

$1435 \eta_{E}$ is the Bingham viscsoity and $T$ is the temperature.

1436

1437 Dieudé-Fauvel et al. (2009) proposed a VTF model (Eq.25) to measure the viscosity of 1438 sludge as a function of temperature:

$1439 \eta=a \exp \left(\frac{b}{T-T_{o}}\right)+c$

1441 where $a, b$ and $c$ are the dimensionless coefficients and $T_{o}$ is the standard temperature $1442(293.15 \mathrm{~K})$. 
1444 Jiang et al. (2007), on the other hand, utilized another form of expression, (Eq.26), to 1445 estimate the temperature effect on the viscosity of sludge in their work to develop a 1446 hydrodynamic model for membrane reactor:

$1447 \ln \left(\frac{\eta}{\eta_{o}}\right) \approx a+b\left(\frac{T_{o}}{T}\right)+c\left(\frac{T_{o}}{T}\right)^{2}$

1448 where $\eta$ and $\eta_{o}$ are the viscosities that corresponded to $T$ and $T_{o}$, respectively, and $a, b$ 1449 and $c$ are the empirical coefficients.

1451 Yang et al. (2009) have presented a correlation that described the relationship between 1452 viscosity, mixed liquor suspended solids of bioreactor sludge $\left(\phi_{p}\right)$, and temperature at a 1453 constant shear rate (Eq.27):

$1455 \quad \eta=a \phi_{p}{ }^{b} e^{\frac{E_{a}}{R(T+273.15)}}$

1456

1457 Khalili Garakani et al. (2011) had modified this equation and proposed a generalized 1458 correlation (Eq.28) that includes the effect of shear rate on apparent viscosity and verified it 1459 based on the experiment results of Yang et al. (2009):

1460

1461

$\eta=a \frac{\phi_{p}^{b}}{\dot{\gamma}} e^{\frac{E_{a}}{R(T+273.15)}}$

Eq. 28 
1462 The correlation shows a good agreement with the experimental data within the solids 1463 content of the work.

1465 However, it was observed that thermal history may have a strong impact on the viscosity of

1466 sludge. Baudez et al., (2013b) have examined the viscosity of anaerobic digested sludge

1467 after heating and cooling and found that the Bingham viscosity increased. It was suggested

1468 that solids might have converted to dissolve compound and this process is partially

1469 irreversible. Therefore, the usual expression to model temperature dependence of sludge

1470 can no longer be applied due to change in sludge composition during the process of heating

1471 and cooling (Baudez et al., 2013b).

1472

\section{4.3. Effect of bound water content on viscosity}

1474 Few researchers have examined the effect of bound water content on the limit viscosity of 1475 sludge. Sozanski et al. (1997) observed a drop in sludge viscosity as the water content 1476 increased, which has previously reported by Forster (1983), and described the behavior 1477 with an exponential function (Eq.29). This behavior may be explained by the change in floc 1478 structure and presence of extracellular polymeric substances on the sludge surface (Liao et 1479 al., 2000).

$1482 W_{k,}$ and $W$ are the critcal water content and water content of the samples. $\eta_{B^{\prime}}, \eta$ are the 1483 plastic viscosity, apparent viscsoity (Bingham mode), respectively. 
1485 Recent development of new technologies in the wastewater treatment process, such as 1486 membrane bioreactor, has urged researchers to consider different experimental conditions 1487 when characterising sewage sludge. For instance, Seyssiecq et al. (2008) has considered the 1488 effect of aeration rate on the viscosity of sludge when performing an in situ rheological 1489 characterization of sludge in aeration bioreactors. It was observed that the viscosity of the 1490 sludge decreased significantly at low shear rate but was almost independent of aeration 1491 rates. At high shear rate, mechanical shearing was the dominant factor in that the structural 1492 reconfiguration of sludge was independent of the presence of air. The experiment has 1493 demonstrated an overall decrease in shear-thinning properties of aerated sludge compared 1494 to non-aerated, with a plateau at high aeration rates. The knowledge of flow behavior for 1495 aerated suspensions is important to understand the phenomenon occurring close to a 1496 membrane, such as fouling or clogging (Seyssiecq et al., 2008).

\section{5. Yield Stress}

1498 The issue of whether yield stress really exists is still being debated. The main reason is that 1499 no equipment, so far, allows researchers to measure the shear stress of sludge at very low 1500 shear rates without being affected by wall-slip or end effects. Besides that, the concept of 1501 yield stress is not well-defined. There is variation in terms of rheological models and 1502 experimental methods used among researchers to determine the yield stress of a material. It 1503 is generally accepted that a rheological model that includes a yield stress term can be used 1504 to represent the flow behavior of sludge over a limited shear rate range, but does not 1505 necessary indicate that the sludge is a yield stress fluid (Barnes, 1999). Baudez and Coussot 
1506 (2001) as well as Mori et al., (2006) believed sludge exhibits yield stress in contrast to 1507 Valioulis (1980). Based on a review paper by Seyssiecq, et al. (2003), with the measuring 1508 apparatus being more advanced, it is commonly admitted among researchers that yield 1509 stress does exist in aggregated concentrated sludge. Indeed, a precise quantitative 1510 knowledge of the yield stress is vital to determine the optimum operating conditions of 1511 various operations in wastewater treatment, notably mixing and pumping. Yield stress is 1512 generally defined as minimum applied stress required for a material to flow continuously.

1513 Yield stress is often used to characterize sludge as it indicates the structure resistance due to 1514 applied shear rate or stress, therefore giving researchers a sense of the material's network 1515 strength and structure. With the presence of a yield stress, the sludge is known as 1516 viscoplastic material. Spinosa and Lotito (2003) summarises the importance of yield stress 1517 on the various sludge treatment operations (such as Stabilization, Dewatering, Storage/ 1518 Transportation, Agricultural use, Land filling, and Incineration) for three different types of 1519 sludge: liquid, paste, solid. They have highlighted that yield stress has high impact on 1520 storage and transportation of sludge regardless of being liquid, paste or solid.

1522 For non-Newtonian fluid, such as sludge, two types of yield stress can be observed in the 1523 flow behavior, which are static and dynamic yield stress. Static yield stress corresponds to 1524 the transition stress between fully elastic and viscoelastic behavior, whereas, dynamic yield 1525 stress refers to the transition stress between viscoelastic and viscous behavior. In sludge 1526 application, it has not been made clear which type of yield stress is most of the researchers 1527 interested in measuring. It is assumed that the dynamic yield stress would be the interest of 1528 all because a material would flow continuously once this value is exceed, which is 
1529 consistent with the general definition of yield stress in sludge application. The 1530 measurement method for yield stress materials with various types of rheometers has been 1531 well documented by Nguyen and Boger (1992) as well as Liddel and Boger (1996). For 1532 sludge application, yield stress measurement is mostly determined experimentally through 1533 dynamic or flow measurement. In dynamic measurement, a yield stress can be obtained by 1534 performing either an oscillatory strain or oscillatory stress sweep at constant frequency. On 1535 the other hand, in flow measurement, a rheogram is obtained and allowed yield stress value 1536 to be calculated by the extrapolation of flow curve to zero shear using rheological models 1537 of sludge eg. Herschel Bulkley (Slatter, 1997; Guibaud, Dollet et al., 2004) or Bingham 1538 model (Mikkelsen, 2001). This method heavily relies on the accuracy of measurement, 1539 which is difficult to obtain due to wall-slip effect. Few authors studied rheological 1540 properties of sludge by combining both dynamic and flow rheometry (Sutapa and Prost, 1541 1996; Baudez, 2002; Baudez and Coussot, 2001). Sutapa and Prost (1996) noticed that the 1542 value of yield stress obtained from dynamic test is higher than yield stress of flow 1543 measurement. However, Mori et al. (2006) found that the flow yield stress was higher 1544 although both were in the same order of magnitude. They justified this by stating that the 1545 yield stress obtained from flow measurements corresponds to when the material begins to 1546 flow, whilst the dynamically measured yield stress is measured at the point just before the 1547 material flows. Recently, the same method had been adopted by Wang et al. (2011a) to 1548 determine the yield stress for conditioned and unconditioned sludge. It was found that the 1549 yield stress determined based on flow measurement correlated well with the ones obtained 1550 the dynamic measurement. Ayol et al. (2006) also conducted flow and dynamic 1551 measurement on conditioned and unconditioned sludge samples. The yield stress was 
1552 determined using the complex modulus (refer to viscoelasticity section for definition) and

1553 critical strain value $\left(\tau_{y}=G^{*} \gamma_{c}\right)$ where the $G^{*}$ decrease dramatically beyond the critcal 1554 strain as the linear viscoelastic raegion ends at this point. They also found that the measured 1555 yield stress for synthetic sludge (Dursun et al., 2004) and anaerobic digested sludge (Ayol 1556 et al., 2006) are shown in good agreement with the peak network strength measured for the 1557 same sample. Although the peak network strength may correspond to the total energy 1558 required to break down the structure of sludge, it is not clear whether that the strength 1559 measured is equivalent to the yield stress of the same sludge samples as no work had 1560 actually been done to examine the relationship between these two. Furthermore, the authors 1561 commented that the geometry dependence in determing these two prevented a direct 1562 comparison.

\section{5.1. Effect of solids concentration, bound water and temperature on} 1564 yield stress

1565 Most authors have examined the effect of solids concentration on the yield stress of sludge.

1566 It is generally agreed among researchers that yield stress tends to increase as the solids 1567 concentration of sludge becomes higher, even for pretreated or conditioned sludge 1568 (Mikkelsen, 2001; Riley and Forster, 2001; Forster, 2002; Seyssiecq et al., 2003; Spinosa 1569 and Lotito, 2003; Wilen et al., 2003; Abu-Jdayil et al., 2010; Khongnakorn et al., 2010, 1570 slatter, 1997). Slatter (1997) relates the yield stress with suspended solids concentration 1571 using the correlation presented in Eq.30. Mori et al. (2006) have examined the rheological 1572 properties of activated sludge with solids concentration range of 2.5 to $57.0 \mathrm{~g} / \mathrm{L}$ and fitted 
1573 the data using Herschel-Bulkley model. They were able to obtain yield stress of sludge

1574 through dynamic measurement and correlate it with solids concentration by using an 1575 exponential law model (Eq.31):

$1576 \quad \tau_{y}=a \frac{T S S^{2}}{T S S_{\max }-T S S}$

$1578 \tau_{y}=a \exp (b \times[T S S])$

1580 where $\tau_{y}$ is yield stress, TSS is total solids suspended as well as $a$ and $b$ which are the

1581 empirical coefficients. Several other researchers have also expressed the relationship 1582 between yield stress of sludge and solids content with an exponential function similar to 1583 Eq. 31 (Battistoni et al., 1993; Riley and Forster, 2001; Abu-Jdayil et al., 2010). Seyssiecq 1584 et al. (2003) have provided a summary of the yield stress model used to describe different 1585 types of sludge under various experimental conditions. Most of the works derived yield 1586 stress value from Bingham model for various solids concentrations of sludge.

1588 However, such models give a yield stress value even when the solids concentration is equal 1589 to zero, which is physically unacceptable. A minimum solids concentration is required to 1590 have a solids structure. In that sense, the power-law model suggested by Baudez (2008, 1591 2011) or Forster (2002) appears more realistic.

1593 Forster also studied the effect of conditioning and pretreatment by using ultrasound on the 1594 rheology of sludge. It was observed that yield stress of sludge reduced after pre-treatment 
1595 and conditioning and the effect was not reversible. In his work, he was able to correlated

1596 yield stress to other two parameters, which are bound water content and surface charges of

1597 sludge, with a logarithmic relationship. This implies that the development of yield stress

1598 can be caused by surface-surface interactions (Forster, 2002). However, this contradicted

1599 with the results of his previous work (Riley and Forster, 2001) as he could not relate yield

1600 stress to bound water content of sludge. Sozanski et al. (1997) were able to express the

1601 relationship between yield stress for diluted sludge and water content in exponential

1602 function.

1603

1604 It is also worth noting that several authors, as summarized in the review paper by Seyssiecq

1605 et al. (2003), have devoted their works to examine the effect of factors, such as temperature

1606 (Manoliadis and Bishop, 1984; Battiston, 1997; Sozanski et al., 1997; Abu-Jdayil et al.,

1607 2010), critical water content, Eq. 32 (Sozanski et al., 1997), total volatile solids (Battiston,

1608 1997) and storage time (Baudez, 2002) on the yield stress of sludge. The behavior of yield

1609 stress is usually related to temperature by an exponential function. Abu-Jdayil et al. (2010)

1610 and Battistoni et al. (1993) have examined the effect of temperature on bioreactor sludge

1611 and anaerobic digested sludge, respectively, and can describe the relationship with

1612 Arrhenius type equation (Eq.33) and Sozanski et al. (1997) presented Eq. 34 for the

1613 correlation between Bingham yield stress and tempreature:

$1614 \tau_{y}=c \exp \left[d\left(W_{k r}-W\right)\right]$

Eq.32

$1615 W_{k r}$ are the critical water content of the sample. $\tau_{y}$ is the yield stress (Bingham model).

$1616 \tau_{y}=C \exp \left(\frac{E_{a}}{R T}\right)$

Eq. 33 
1617 where $C$ is the pre-exponential constant, and $E_{a}$ is the yield stress activation energy, $T$ is

1618 absolute temperature, $R$ is universal gas constant. As for other parameters, the general

1619 form of yield stress model cannot be confirmed due to lack of literature data.

1620

$1621 \quad(W T)_{2}=\frac{1}{T-273,45}\left[\frac{\left(\tau_{y}\right)_{278.45}}{\left(\tau_{y}\right)_{T}}-1\right] \cdot 100$

1622

1623 Mikkelsen (2001) demonstrated that apparent viscosity of activated sludge was directly

1624 proportional to the Bingham yield stress and commented that these parameters can be used

1625 to reflect the number of particle interactions which oppose the flow of suspension.

1627 It seems that most researchers rely on the indirect method which utilizes extrapolation of 1628 various flow models to obtain the yield stress value. The direct measurement of yield stress 1629 should also be done using the vane method, stress growth and stress relaxation method to 1630 verify and compare the yield stress obtained using extrapolation of flow models. However, 1631 it is important to review the suitability of the measurement method to ensure its 1632 compatibility with type of sludge studied and identify any related errors may need to be 1633 considered for correction. For instance, inclined plane test proposed by Coussot and Boyer 1634 (1995) may not be suitable for yield stress measurement of sludge as it cannot cover a wide 1635 shear range and is not relevant for thixotropic fluid.

1637 Various authors such as Ogawa et al. (1997), Zhou et al. (2001) and Berli and Quemada 1638 (2000) have derived yield stress models to determine the yield stress values of colloidal 
1639 suspensions which can be useful for primary sludge as it acts as a suspension. These

1640 models are presented in Table 1 as well as a description of their application.

1641 Table 1: Yield stress models for various suspensions

\begin{tabular}{|c|c|c|}
\hline Author & Model & Description \\
\hline Ogawa et al. (1997) & $\tau_{y}=\frac{\phi U(r)}{a d^{3}}$ & $\begin{array}{l}\text { Yield stress model that takes } \\
\text { into account the volume } \\
\text { fraction }(\phi) \text {, total interaction } \\
\text { potential } U(r) \text {, and particle } \\
\text { diameter }(d) \text {; a is a model } \\
\text { parameter. }\end{array}$ \\
\hline Zhou et al. (2001) & $\tau_{y}=B \frac{\phi^{v}}{d^{2}}$ & $\begin{array}{l}\text { Yield stress model that takes } \\
\text { into account the volume } \\
\text { fraction }(\phi) \text {, Bond strength } \\
\text { coefficent }(B) \text { particle } \\
\text { diameter }(d) \text {, and power law } \\
\text { exponent }(v) \text { that is related } \\
\text { to the microstructure. }\end{array}$ \\
\hline Berli and Quemada (2000) & $\tau_{y}=X \tau_{0}$ & $\begin{array}{l}\text { Yield stress model that is } \\
\text { valid for dense suspensions } \\
\text { (i.e. } \phi>\phi_{\sigma} \text { ), } \mathrm{X} \text { is a } \\
\text { rheological parameter, and } \\
\tau_{c} \text { is the critical shear stress. }\end{array}$ \\
\hline
\end{tabular}


1642 At the moment, there is also no consistent correlation that relates yield stress to any of the

1643 physical parameters of sludge such as the origin of the sludge and the experimental

1644 conditions employed in each research work different from one to another. This implies that

1645 yield stress model can only be determined empirically, which is not desirable. The effect of

1646 physico-chemical properties such as temperature or $\mathrm{pH}$ on yield stress of sludge has not

1647 been examined properly. This could be due to the fact that most yield stress results are not

1648 reproducible and can vary by several orders of magnitude even if the experimental

1649 conditions were to remain the same. The result inconsistencies are usually associated with

1650 thixotropic property of sludge and equipment defects when measuring at low shear rate

1651 (Moller, Mewis et al., 2006). Effect of thermal history on yield stress of sludge should be

1652 examined as well. It is observed that yield stress of sludge which undergone heating and

1653 cooling is less than original sludge at the same temperature and without thermal history

1654 (Baudez et al., 2013b). Therefore, it is important to develop a simple, systematic and 1655 relevant procedure to characterize yield stress of sludge. Besides that, it is also important to 1656 clarify the type of yield stress one is measuring i.e. static or dynamic yield stress. This 1657 allows researchers to compare results and discuss any issues related to the measurement 1658 easily. This hopefully can accelerate the development of rheological model that can be used 1659 to evaluate significance of yield stress in sludge rheology.

\section{6. Thixotropy}

1661 Thixotropy refers to the time-dependent disintegration of internal structure (Figure 4) as a 1662 result of the application of shear stress (Baxter 1988; Battistoni 1997; Tixier et al. 2003 a, b 1663 ; Baudez 2006; Baudez 2008). 
1664 According to Baudez (2008), below a critical shear stress, colloidal forces tend to rebuild

1665 the solids structure (physical aging) and shearing forces tend to break the solids structure

1666 (shear rejuvenation). As soon as the critical shear is reached, the solids structure is

1667 completely collapsed, and fluid starts flowing which the relationship between the shear rate

1668 and the shear stress can be defined with a truncated power-law (Baudez, 2008). In practice,

1669 thixotropic effects can alter pipe transportation by producing clog if the wall shear stress is

1670 not high enough to maintain a homogenous flow. Therefore, change of flow behavior of

1671 sludge over time is important to be considered in pipeline and pumping system design.

1672 This worsens by increasing sludge concentration as shear stress for continuous flow is a

1673 power law function of solids concentration. Besides that, the thixotropic behavior would

1674 results in structural build-up of sludge over a long retention time in the mixing tank or

1675 reactors and form stagnant region if not sheared properly, which is undesirable. Hence, a

1676 good knowledge of thixotropic property is crucial to enable development of an efficient

1677 stirring or mixing mechanism to optimize the treatment process with minimum cost.

1678

1680

1681

1682

\section{Figure 4: Change of viscosity over time when stress applied and removed for just shear-thinning material (black line) versus shear-thinning thixotropic material (red line), image courtesy to google}

1683 Several studies had highlighted the controversies of whether thixotropic property of sludge

1684 was existed or merely an erroneous interpretation. This property makes it extremely

1685 difficult to characterise sludge according to a specific rheometric technique (Seyssiecq et

1686 al. 2003; Mori et al. 2006). Hence, there is always inconsistency in literature in terms of

1687 sludge characterisation and behaviour (Seyssiecq, Ferrasse et al. 2003; Mori et al. 2006). 
1688 Tixier et al. $(2003 \mathrm{a}, \mathrm{b})$ found that the area of the hysteresis loop varied according to the 1689 nature of sludge.

1691 However, Baudez (2006) demonstrated that the hysteresis loop mostly comes from the 1692 rheological procedure and the accuracy of the rheometer.

1694 That may explain why Seyssiecq et al. (2003) showed that few researchers had attempted to 1695 model the thixotropic characteristic of sewage sludge but was unsuccessful, while most of 1696 them merely mentioned this property in their studies to remind possible errors might exist 1697 in the rheological measurement.

1699 Other characterization methods include step change in shear rate and shear stress as well as 1700 dynamic moduli, which are detailed elsewhere (Mewis and Wagner, 2009). These two 1701 methods were able to provide a basis to evaluate the thixotropic effect although the level of 1702 understanding of shear history dependence of microstructure is still limited (Mewis and 1703 Wagner, 2009).

1705 Recently, Baudez $(2004 ; 2008)$ has presented a new technique, which is the reconstruction 1706 of the velocity profile, to measure the dual rheological behavior of sewage sludge. In this 1707 work, he was able to model the behavior of sludge using a unique equation which consisted 1708 of a solid and liquid component as well as a structural parameter, $\lambda$, measured as a function 1709 of time, to characterize the time-dependency of sludge. This parameter had also been 1710 adopted by several other researchers to develop thixotropic model that can be used to 
1711 characterize time-dependent behavior of yield stress fluids (Labanda et al., 2004; Dullaert

1712 and Mewis, 2005; Alexandrou et al., 2009; Mewis and Wagner, 2009; Livescu et al., 2011).

1713 It is defined as a measure of the degree of structure in the suspension, having a value in the

1714 range of zero (fully broken) to 1 (fully structured) (Toorman, 1997). Several researchers had

1715 demonstrated the possibility to relate the structural parameter to the rheological parameters

1716 of non-Newtonian fluid, notably yield stress (Toorman, 1997) and viscosity (Labanda and

1717 Llorens, 2008). However, most of the models proposed are not readily used in sludge

1718 application as they are still in developing stage and has not been verified with experimental

1719 results. Most importantly, these models involve multiple variables, which are complex to

1720 solve, and required significant simplification to improve the practicability of these models.

1722 In contrast to the large number of models that have been proposed, there are few systematic 1723 data that can be used to evaluate the thixotropy of sludge for model verification, which has 1724 seriously hinders the progress in this field. Recently several researchers had devoted their 1725 works to study the impact of sludge age on the sludge treatment operations, but did not 1726 present any correlations that could contribute to the characterization of the thixotropic 1727 property of sludge (Ekama, 2010; Çiğgin et al., 2011; Hocaoglu et al., 2011).

1729 There has been a growing interest among researchers to develop a reliable model for 1730 thixotropic characterization of various yield stress materials, but not specifically for sludge.

1731 Currently, most of the models are general. The measurement accuracy of thixotropic 1732 properties is often met with skepticism from researchers as there are no consistent 
1733 laboratory protocols, reliable devices or even established parameters that can characterize

1734 this property.

1735

\section{7. Viscoelasticity}

1737 Sludge exhibits viscoelasticity which means that it behaves as elastic solids and liquid and

1738 when the applied stress reduces to zero, a partial elastic recovery is observed (Figure 5).

1739 The partial recovery may be related to storage of energy in inter-particle bounds.

Figure 5: Elastic and viscous response of a viscoelastic material to applied and

1743 Under applied stress, the sludge will behave as solids initially, but as a liquid eventually

1744 due to the breakdown of floc structure. The viscoelastic properties are obtained through

1745 dynamic measurement by applying a sinusoidal deformation and measuring a sinusoidal

1746 stress (stress and viscous component) in response to deformation (Chhabra and Richardson,

1747 2008). The storage modulus ( $G^{\prime}$, ratio of elastic stress over strain) and loss modulus $\left(G^{\prime \prime}\right.$,

1748 the ratio of viscous stress over strain) are corresponding to the amount of energy stored and

1749 dissipated during deformation. The effects of these two moduli are combined into the

1750 complex modulus $\left(G^{*}=\frac{\tau^{*}}{\gamma^{*}}\right)=G^{\prime}+i G^{\prime \prime}$, which indicate the sludge's overall resistance to

1751 deformation (Ayol et al., 2006). When $G^{\prime}>G^{\prime \prime}$, implies that elastic behavior is more

1752 dominant than viscous behavior and vice versa. They can be calculated from Eq. (35)

1753 (Seyssiecq, et al. 2003). 
$1754 \quad G^{\prime \prime}=\frac{\eta \omega^{2}}{1+\lambda^{2} \omega^{2}}, G^{\prime}=\frac{n \lambda \omega^{2}}{1+\lambda^{2} \omega^{2}}$

Eq.35

1755 where $\omega$ is oscillation frequency and $\lambda$ is structural parameter. A complete review on the

1756 concept of dynamic measurement with sinusoidal oscillations can be found in the work of

1757 Seyssiecq et al. (2003). At present, there is no consistent correlation that can relate the

1758 parameter in dynamic measurement to the rheological parameters in flow measurement.

1759

1760 Chen et al. (2005) has demonstrated that the complex modulus of sludge can be 1761 significantly affected the addition of coagulant polymer. The addition of polymer would

1762 cause all the sludge samples to form more rigid solids and therefore, storage modulus 1763 increases with increasing polymer dosing, which is consistent with the results obtained by

1764 (Wang, et al., 2011a). The authors believed that the variation in $G^{*}$ due to polymer addition 1765 may be explained by change of network strength of floc caused by the formation of 1766 bridging between cationic polymers and negatively charged sludge particles. Frequency 1767 sweeps from the work of (Wang et al., 2011a) revealed that the G'> G' indicating that the 1768 elastic behaviour was dominant over the viscous behaviour until a critical point was 1769 reached then $G$ ' > $>$ '. This trend was also present for conditioned sludge, however, it 1770 extended over the viscous region, suggesting that for unconditioned anaerobic digested 1771 sludge, the water hold capacity was greater and exhibited less elastic behaviour. The 1772 crossover from $G^{\prime}>G^{\prime \prime}$ to $G$ "' $>G^{\prime}$ is similar to that of solids and pastes suggesting that 1773 sludge behaves in a similar manner. Wang et al. (2011a) also observed gel like behaviour 1774 for low viscosity sludges at high shear rates in the linear viscoelastic regions. They argued 1775 that more energy is stored in the rigid structure of the conditioned anaerobic digested 
1776 sludge which increases its elasticity (G'). Ayol et al.(2006) also conducted dynamic

1777 measurements on conditioned and unconditioned sludge samples and found that the storage

1778 modulus was greater than the loss modulus in the linear viscoelastic range, and the loss

1779 modulus increased whilst the storage modulus decreased beyond the linear viscoelastic

1780 range.

1781

1782 The hydrogel property of granular sludge has been identified by Seviour et al. (2009a)

1783 through dynamic measurement. This work has established a protocol for characterization of

1784 granular sludge and revealed that the macromolecular association is responsible for the

1785 formation of granular sludge under various environmental conditions as well as the yield

1786 response, which can be useful to promote flocculation in wastewater treatment. Also, they

1787 have utilized this technique to explain the structure difference between aerobic sludge

1788 granules and floccular sludge based on the sol-gel transition of extracellular polymeric

1789 substance (EPS) derived from the sludge (Seviour et al., 2009b). Recently, Baudez et al.

1790 (2013a) have identified strong similarity of the viscoelastic behavior of anaerobic digested

1791 and raw sludge with soft glassy material using dynamic measurement. Elastic and loss

1792 modulus is constant in linear viscoelastic region and $G^{\prime}>G^{\prime \prime}$ but at cross over point $G^{\prime \prime}$

1793 reaches its peak, then $G^{\prime}<G^{\prime \prime}$ which is the hallmark of soft-glassy materials. This showed

1794 that soft-glassy material can be used a model fluid.

1795

1796 Based on the literature reviewed, it is shown that the application of dynamic measurement

1797 in sludge characteristion have been restricted to evaluation of visco-elastic properties as 
1798 well as yield stress determination. Besides that, the reliability of these experimental works

1799 is unsure as there are too few studies or results that can be used for evaluation. More

1800 researchers should incorporate this type measurement into their work to explore its

1801 application and potential in sludge characteristaion as it is complementary to a better

1802 understanding of sludge rheology in static mode. Dynamic measurement has proved to be a

1803 useful analysis method to determine the elastic properties of sludge, which can provide a

1804 meaningful insight to the technical matters, such as mixing and pumping, in the wastewater

1805 treatment process. With better understanding of the dynamic behaviour, engineers may

1806 incorporate this parameter into their design to improve the process efficiency.

1808 8. Relationship between sludge rheology and physico-chemistry 1809 interaction

1810 There is little understanding between the rheological properties and actual sludge physico-

1811 chemical behaviour. The works of Forster $(1981 ; 1982 ; 2002)$ illustrate the relationship

1812 between surface chemistry and rheological properties. According to Forster (1982; 2002),

1813 the non-Newtonian behaviour of sewage sludges is related to the materials surface

1814 chemistry, so the surface charge carried by each component. Forster $(1981 ; 1982)$ studied

1815 activated, anaerobically digested and aerobically digested sludges and found that the 1816 relationship between surface charge and rheological properties is controlled by the ionic

1817 strength of liquoras well as the chemical nature of sludge surfaces. For activated sludge,

1818 Forster (1982) found that polysaccharides influenced the surface charge. Forster (1982)

1819 found that the viscosity was reduced by adding cellulose;hence, the influence of 
1820 polysaccharide on surface charges is significant. Forster (1982) was unsuccessful in 1821 determining the relationship between surface charge and rheological properties for other 1822 types of sludge and emphasised the neccessity of research on the surface chemistry of 1823 sludge and its influence on the rheological properties. No model was developed to be able 1824 to describe the relation between surface charge and viscosity of activated sludge. However, 1825 in his 2002 study of the rheological and physico-chemical characteristics of sewage 1826 sludges, Forster was able to develop a rule that described the influence of surface charge 1827 (Eq.36) and water content (Eq.37) on yield stress (Forster 2002).

1829 Surface charge $=-a \operatorname{Ln}\left(\tau_{y}\right)-b$ Eq.36 water content $=a \operatorname{Ln}\left(\tau_{y}\right)+b$

1831 Where $\tau_{y}$ is the yield stress and $a$ and $b$ are model parameters.

1833 Tixier et al. (2003a) have investigated the effect of surface charge on limiting viscosity of 1834 activated sludge by varying $\mathrm{pH}$ and the cation concentration (calcium and sodium ions). A 1835 smallr decrease in $\mathrm{pH}$ and cation concentration decreased limiting viscosity which indicates 1836 that the sludge particle surface charge affects viscosity. This intraction was shown through 1837 the linear correlation between zeta potential and limiting viscosity. They have suggested 1838 that the effect of $\mathrm{pH}$ variation on viscosity could be related to the change of repulsion 1839 forces between flocs and thickness of double layer, as indicated by the zeta-potential. This 1840 is inconsistent with Sanin (2002) observation and their conclusion that increasing PH 1841 increas negetive charge on flocs which increases repulsion and hence expansion of floc 
1842 matrix. However, Mu et al. (2007) commented that the limiting viscosity of sludge did not

1843 respond well to $\mathrm{pH}$ variation. Recently, $\mathrm{Li}$ and $\mathrm{Yu}$ (2011) have commented in their review

1844 paper that this matter still remains contraversial whether limiting viscosity is sensitive to

1845 pH change or not.

1847 The effect of cation concentration on limiting viscosity was shown to be in good agreement 1848 with the work of Sanin (2002) and Pevere et al. (2007) and may be related to the 1849 compression of double layer, change of electrostatic repulsion between sludge floc and the 1850 salt concentration in the suspension. Sanin (2002) also examined the influence of 1851 conductivity on the rheology of activated sludge. They observed thatincreasing 1852 conductivity decreased the apparent viscosity Sanin (2002) argued that this was due to the 1853 compression of the electrical double layer around particles which results in a more compact 1854 floc structure.

1856 Mori et al. (2006) calculated the magnitude of the energy of cohesion $\left(E_{\varepsilon}\right)$ of the 3D 1857 network of sludge (Eq. 38). This energy was used to determine the extent of interaction in 1858 flocculated structure. This method requires dynamic measurements.

$1859 \quad E_{e}=\frac{1}{2} \tau_{y}$ dywamie $\gamma_{c}$ Eq. 38

1861 The dynamic yeild stress $\left(\tau_{y, \text { dynamia }}\right)$ and energy of cohesion of the 3D sludge network $1862\left(E_{c}\right)$ were found to be proportional $\left(\tau_{y, \text { aymamie }}=\alpha \cdot E_{\varepsilon}\right)$ because $\gamma_{\varepsilon}$ is almost constant for 1863 different concentration of sludge. Mori et al. (2006) developed an empirical model to 
1864 describe the relationship between the energy of cohesion of the 3D network of sludge and 1865 suspended solids concentration (Eq. 39).

$1866 E_{c}=\operatorname{aexp}[b(T S S)]$

1867 where $\mathrm{a}$ and $\mathrm{b}$ are parameters.

\section{9. Conclusion}

1869 Rheological measurements have proved to be of great importance to quantitatively estimate 1870 the physical consistency of sewage sludge, and impart important data for wastewater 1871 treatment process optimization and design. Of all the rheological properties, the 1872 characterization of sludge thixotropic property has been the most difficult measurements.

1873 Even though many models have been proposed for this, there is little consistent data that 1874 can be used to verify the models due to the lack of reliable methodology to measure this 1875 property. A review of the literature presents:

1876 - Sludge is always non-Newtonian

1877 - exhibits a yield stress or not,

1878 - is shear-thinning and thixotropic.

1879 - At high shear rate, sludge behaves as thixotropic colloidal suspension, but

1880 - At low shear rate exhibits polymeric behavior.

1881 - Sewage sludge at high solids concentrations (3-10\%) behaves as a complex mixture 1882 whose rheological behavior is highly dependent on the treatment process it is $1883 \quad$ undergoing

1884 - A combined Herschel-Bulckley and Bingham model describes sludge behavior over 1885 the full range of shear rates 


\section{Acknowledgment:}

1898 The authors are grateful for financial support which provided by RMIT Research and 1899 Innovation Office, Melbourne Water and South-East Water companies.

\section{References}

1902

1903 Abu-Jdayil, B., Banat, F., Al-Sameraiy, M., 2010. Steady rheological properties of rotating 1904 biological contactor (RBC) Sludge. Journal of Water Resource and Protection 2(1), 1-7. 
1906 Abu-Orf, M.M., Örmeci, B., 2005. Measuring sludge network strength using rheology and 1907 relation to dewaterability, filtration, and thickening - laboratory and full-scale experiments. 1908 Journal of Environmental Engineering 131(8), 1139-1146.

1909

1910 Alexandrou, A.N., Constantinou, N, Georogiou, G., 2009. Shear rejuvenation, aging and 1911 shear banding in yield stress fluids. Journal of Non-Newtonian Fluid Mechanics 158 (1-3), 1912 6-17.

1913

1914 Allen, D.G., Robinson, C.W., 1990. Measurement of rheological properties of filamentous 1915 fermentation broths. Chemical Engineering Science 45(1), 37-48.

1916

1917 Ayol, A., Dentel, S.K., 2005. Enzymatic treatment effects on dewaterability of 1918 anaerobically digested biosolids II: laboratory characterizations of drainability and 1919 filterability. Process Biochemistry 40(7), 2435-2442.

1920

1921 Ayol, A., Dentel, S.K., Filibeli, A., 2006. Toward efficient sludge processing using novel 1922 rheological parameters: dynamic rheological testing. Water Science \& Technology 54(4), 1923 17-22.

1924

1925 Babbit, H.E., Caldwell, D.H., 1939. Laminar Flow of Sludges in Pipes with Special 1926 Reference to Sewage Sludge. Illinois, University of Illinois Bulletin. 1927 
1928 Bache, D.H., Papavasilopoulos, E.N., 2000. Viscous behaviour of sludge centrate in 1929 response to polymer conditioning. Water Research 34(1), 354-358.

1930

1931 Barnes, H.A., 1997. Thixotropy - a review. Journal of Non-Newtonian Fluid Mechanics $193270(1-2), 1-33$.

1933

1934 Barnes, H.A., 1999. The yield stress - a review or ' $\pi \alpha \nu \tau \alpha \rho \varepsilon \imath$ ' - everything flows. Journal 1935 of Non-Newtonian Fluid Mechanics 81(1-2), 133-178.

1936

1937 Baroutian S., Eshtiaghi N., Gapes D., 2013. Rheology of a primary and secondary sewage 1938 sludge mixture: dependency on temperature and solids concentration. Bioresource 1939 Technology 140, 227-233.

1941 Battistoni, P., 1997. Pretreatment, measurement execution procedure and waste 1942 characteristics in the rheology of sewage sludges and the digested organic fraction of 1943 municipal solids wastes. Water Science and Technology 36(11), 33-41.

1945 Battistoni, P., Fava, G., Stanzini, C., Cecchi, F., Bassetti, A., 1993. Feed characteristics and 1946 digester operative conditions as parameters affecting the rheology of digested municipal 1947 solids wastes. Water Science \& Technology 27(2), 37-45.

1948

1949 Baudez, J.C., 2002. Rheology and physico-chemistry of pasty sewage sludge in view of 1950 storing and spreading. La Houille Blanche 98-103. 
1952 Baudez, J.C., 2004. New technique for reconstructing instantaneous velocity profiles from 1953 viscometric tests: Application to pastry material. Journal of Rheology 48(1), 69-82.

1954

1955 Baudez, J.C., 2006. About peak and loop in sludge rheograms. Journal of Environmental 1956 Management 78(3), 232-239.

1957

1958 Baudez, J.C., 2008. Physical aging and thixotropy in sludge rheology. Applied Rheology $195918(1), 13459-13466$.

1960

1961 Baudez, J.C., Ayol, A., Coussot, P., 2004. Practical determination of the rheological 1962 behavior of pasty biosolids. Journal of Environmental Management 72(3), 181-188.

1963

1964 Baudez, J.C., Coussot, P., 2001. Rheology of aging, concentrated, polymeric suspensions: 1965 application to pasty sewage sludges. Journal of Rheology 45 (5), 1123-1139.

1966

1967 Baudez, J.C., Ginisty, P., Peuchot, C., Spinosa, L., 2007. The preparation of synthetic 1968 sludge for lab testing. Water Science \& Technology 56 (9), 67-74.

1969

1970 Baudez, J.C., Markis, F., Eshtiaghi, N., Slatter, P.T., 2011. The rheological behaviour of 1971 anaerobic digested sludge. Water Research 45(17), 5675-5680.

1972 
1973 Baudez, J.C., Gupta, R., Eshtiaghi, N., Slatter, P.T., 2013a. The viscoelastic behaviour of 1974 raw and anaerobic digested sludge: strong similarities with soft-glassy materials, in press, 1975 Water Research, 47, 173-180.

1976

1977 Baudez, J.C., Slatter, P.T., Eshtiaghi, N., 2013b. The impact of temperature on the 1978 rheological behaviour of anaerobic digested sludge. Chemical Engineering Journal 2151979 216, 182-187.

1980

1981 Baxter, T.E., 1988. The effects of sludge rheology on mixing in the anaerobic digestion 1982 process. $\mathrm{PhD}$ thesis, Kansas University.

1983

1984 Behn, V.C., 1962. Experimental determination of sludge-flow parameters. Journal of the 1985 Sanitary Engineering Division 88(SA3), 39-54.

1986

1987 Bellon, L., Gibert, M., Hernández, R., 2007. Coupling between aging and convective 1988 motion in a colloidal glass of Laponite. The European Physical Journal B - Condensed 1989 Matter and Complex Systems 55(1), 101-107.

1990

1991 Berli, C.L.A., Quemada, D., (2000). Prediction of the interaction potential of microgel 1992 particles from rheometric data. Comparison with different models. Langmuir 16(26), 1993 10509-10514.

1994 
1995 Bhattacharya. S.N., 1981. Flow characteristics of primary and digested sewage sludge.

1996 Rheologica Acta 20(3), 288- 298.

1997

1998 Bougrier, C., Albasi, C., Delgenès, J.P., Carrère, H., 2006. Effect of ultrasonic, thermal and 1999 ozone pre-treatments on waste activated sludge solubilisation and anaerobic 2000 biodegradability. Chemical Engineering and Processing: Process Intensification 45(8), 7112001718.

2002

2003 Brannock, M., Wang, Y., Leslie, G., 2010. Mixing characterisation of full-scale membrane 2004 bioreactors: CFD modelling with experimental validation. Water Research 44(10), 318120053191.

2006

2007 Brar, S.K., Verma, M., Tyagi, R.D., Surampalli, R.Y., Valéro, J.R., 2008. Bacillus 2008 thuringiensis fermentation of primary and mixed sludge: rheology and process 2009 performance. Journal of Environmental Engineering 134(8), 659-670.

2010

2011 Brar, S.K., Verma, M., Tyagi, R.D., Valéro, J.R., Surampalli, R.Y., 2005. Sludge based 2012 Bacillus thuringiensis biopesticides: Viscosity impacts. Water Research 39(13), 3001-3011. 2013

2014 Brisbin, S.G., 1957. Flow of concentrated raw sludge in pipes. Proceeding of the American 2015 Society of Civil Engineering 83(SA1), 1557.

2016 
2018 Chaari, F., Racineux, G., Poitou, A., Chaouche, M., 2003. Rheological behaviour of sewage 2019 sludge and strain-induced dewatering. Rheologica Acta 42(3), 273-279.

2021 Chen, B.H., Lee, S.J., Lee, D.J., 2005. Rheological characteristics of the cationic 2022 polyelectrolyte flocculated wastewater sludge. Water Research 39(18), 4429-4435.

2024 Chhabra, R.P., Richardson, J.F., 2008. Non-Newtonian flow and applied rheology 2025 engineering applications. $2^{\text {nd }}$ Edition, Elsevier.

2026

2027 Chu, C.P., Wu, C.M., Wu, Y.S., Lin, C.C., Chung, Y.J., 2007. Structural analysis and 2028 dewatering characteristics of waste sludge from WWTP MBR. Separation Science and 2029 Technology 42(16), 3713-3726.

2030

2031 Çiğgin, A.S., Rossetti, S., Majone, M., Orhon, D., 2011. Effect of feeding and sludge age 2032 on acclimated bacterial community and fate of slowly biodegradable substrate. Bioresource 2033 Technology 102(17), 7794-7801.

2034

2035 Coussot, P., Boyer, S.P., 1995. Determination of yield stress fluid behaviour from inclined 2036 plane test. Rheologica Acta 34(6), 534-543.

2037

2038 Dick, R.I., Buck, J.H., 1985. Measurement of activated sludge rheology. American Society 2039 of Civil Engineers Proceedings of the Environmental Engineering Division Specialty 2040 Conference, Boston, MA. 
2041 Dick, R.I., Ewing, B.B., 1967. The rheology of activated sludge. Journal - Water Pollution 2042 Control Federation 39(4), 543-560.

2043

2044 Dieudé-Fauvel, E., Van Damme, H., Baudez, J.C., 2009. Improving rheological sludge 2045 characterization with electrical measurements. Chemical Engineering Research and Design 2046 87(7), 982-986.

2047

2048 Dullaert, K., Mewis, J., 2005. Thixotropy: Build-up and breakdown curves during flow. 2049 Journal of Rheology 49(6), 1213-1230.

2050

2051 Dursun, D., Ayol, A., Dentel, S.K., 2004. Physical characteristics of a waste activated 2052 sludge: conditioning responses and correlations with a synthetic surrogate. Water Science 2053 \& Technology 50 (9), 129-136.

2054

2055 Ekama, G.A., 2010. The role and control of sludge age in biological nutrient removal 2056 activated sludge systems. Water Science and Technology 61(7), 1645-1652.

2057

2058 Eshtiaghi, N., Markis, F., Slatter, P.T., 2012a. The laminar/turbulent transition in a sludge 2059 pipeline. Water Science and Technology Vol.65 (4), 697-702. 
2061 Eshtiaghi N., Yap, S.D., Markis, F., Baudez, J.C., Slatter, P. 2012b. Clear model fluids for 2062 peculiar rheological properties of thickened Digested sludge. Water Research 46, 301420633022.

2064

2065 Fonts, I., Kuoppala, E., Oasmaa, A., 2009. Physicochemical properties of product liquid 2066 from pyrolysis of sewage sludge. Energy \& Fuels 23(8), 4121-4128.

2067

2068 Forster, C.F., 1981. Preliminary studies on the relationship between sewage sludge 2069 viscosities and the nature of the surfaces of the component particles. Biotechnology Letters $2070 \quad 3(12), 707-712$.

2071

2072 Forster, C.F., 1983. Bound water in sewage sludge and its relationship to sludge surfaces 2073 and sludge viscosities. Journal of chemical technology and biotechnology. Biotechnology 2074 33(1), 76-84.

2075

2076 Forster, C.F., 2002. The rheological and physico-chemical characteristics of sewage 2077 sludges. Enzyme and Microbial Technology 30(3), 340-345.

2078

2079 Gasnier, L., Florentz, M., Soleilhavoup, S., 1986. Utilisation des méthodes rhéologiques 2080 pour le conditionnement des boues de station d'épuration. Tech. Sci. Méth., Génie Urbain 2081 Génie Rural 81(1), 35-43.

2082 
2083 Guibaud, G., Dollet, P., Tixier, N., Dagot, C., Baudu, M., 2004. Characterization of the 2084 evolution of activated sludges using rheological measurements. Process Biochemistry $208539(11), 1803-1810$.

2086

2087 Hiemenz, P.C., Rajagopalan, R., 1997. Principles of colloid and surface chemistry. New 2088 York, Marcel Dekker.

2089

2090 Ho, J., Sung, S., 2009. Effects of solids concentrations and cross-flow hydrodynamics on 2091 microfiltration of anaerobic sludge. Journal of Membrane Science 345(1-2), 142-147.

2092

2093 Hocaoglu, S.M., Insel, G., Ubay Cokgor, E., Orhon, D., 2011. Effect of sludge age on 2094 simultaneous nitrification and denitrification in membrane bioreactor. Bioresource 2095 Technology 102(12), 6665-6672.

2096

2097 Ho, J., Sung, S., 2009. Effects of solid concentrations and cross-flow hydrodynamics on 2098 microfiltration of anaerobic sludge; Journal of Membrane Science 345(1-2), 142-147.

2100 Hou, C.H., Li, K.C., 2003. Assessment of sludge dewaterability using rheological 2101 properties. Journal of the Chinese Institute Engineers 26(2), 221-226.

2102

2103 Jiang, T., Kennedy, M.D., Yoo, C., Nopens, I., Van der Meer, W., Futselaar, H., Schippers, 2104 J.C., Vanrolleghem, P.A., 2007. Controlling submicron particle deposition in a side-stream 
2105 membrane bioreactor: A theoretical hydrodynamic modelling approach incorporating 2106 energy consumption. Journal of Membrane Science 297(1-2), 141-151.

2108 Jin, B., Wilen, B.M., Lant, P., 2004. Impacts of morphological, physical and chemical 2109 properties of sludge flocs on dewaterability of activated sludge. Chemical Engineering 2110 Journal 98(1-2), 115-126.

2112 Jolis, D., 2008. High-solids anaerobic digestion of municipal sludge pretreated by thermal 2113 hydrolysis. Water Environment Research 80(7), 654-662.

2115 Khalili Garakani, A.H., Mostoufi, N., Sadeghi, G., Hosseinzadeh, M., Fatourechi, M., 2116 Sarrafzadeh, M.H., Mehrnia, M.R., 2011. Comparison between different models for 2117 rheological characterisation of activated sludge. Iranian Journal of Environmental Health 2118 Sciences \& Engineering 8(3), 255-264.

2119

2120 Khongnakorn, W., Mori, M., Vachoud, L., Delalonde, M.L., Wisniewski, C., 2010.

2121 Rheological properties of sMBR sludge under unsteady state conditions. Desalination $2122250(2), 824-828$.

2123

2124 Kim, T.H., Lee, S.R., Nam, Y.K., Yang, J., Park, C., Lee, M., 2009. Disintegration of 2125 excess activated sludge by hydrogen peroxide oxidation. Desalination 246(1-3), 275-284. 2126 
2127 Krieger, I.M., Dougherty, T.J., 1959. A mechanism for non-newtonian flow in suspensions

2128 of rigid spheres. Transactions of the Society of Rheology 3, 137-152.

2129

2130 Kurath, S.F., Larson, W.S., 1990. Capillary viscometry on a rheologically complex coating 2131 color. Tappi Journal 73(9). 235-241.

2132

2133 Labanda, J., Llorens, J., 2008. Effect of aging time on the rheology of Laponite dispersions.

2134 Colloids and Surfaces A: Physicochemical and Engineering Aspects 329(1-2), 1-6.

2135

2136 Labanda, J., Marco, P., Llorens, J., 2004. Rheological model to predict the thixotropic

2137 behaviour of colloidal dispersions. Colloids and Surfaces A: Physicochemical and 2138 Engineering Aspects 249(1-3), 123-126.

2139

2140 Laera, G., Giordano, C., Pollice, A., Saturno, A., Mininni, G., 2007. Membrane bioreactor 2141 sludge rheology at different solids retention times. Water Research 41 (18), 4197-4203.

2142

2143 Landel, R.F., Moser, B.G., Bauman, A.J., 1965. Rheology of concentrated suspensions 2144 Effect of a surfactant. Proceedings of the 4th International Congress on Rheology, New 2145 York, Interscience.

2146

2147 Li, WW., Yu, HQ., 2011. Physicochemical characteristics of anaerobic H2-producing 2148 granular sludge. Bioresource Technology 102(18), 8653-8660. 
2150 Liao, B.Q., Allen, D.G., Droppo, I.G., Leppard, G.G., Liss, S.N., 2000. Bound water

2151 content of activated sludge and its relationship to solids retention time, floc structure, and

2152 surface properties. Water Environment Research 72(6), 722-730.

2153

2154 Liddel, P.V., Boger, D.V., 1996. Yield stress measurements with the vane. Journal of Non-

2155 Newtonian Fluid Mechanics 63(2-3), 235-261.

2156

2157 Livescu, S., Roy, R.V., Schwartz, L.W., 2011. Leveling of thixotropic liquids. Journal of

2158 Non-Newtonian Fluid Mechanics 166(7-8), 395-403.

2159

2160 Lotito, V., Spinosa, L., Mininni, G., Antonacci, R., 1997. The rheology of sewage sludge at 2161 different steps of treatment. Water Science and Technology 36(11), 79-85.

2162

2163 Manoliadis, O., Bishop, P.L., 1984. Temperature effect on rheology of sludges. Journal of 2164 Environmental Engineering 110(1), 286-290.

2165

2166 Martin, I., Pidou, M., Soares, A., Judd, S., Jefferson, B., 2011. Modelling the energy 2167 demands of aerobic and anaerobic membrane bioreactors for wastewater treatment. 2168 Environmental Technology 32(9), 921-932.

2169

2170 Mewis, J., Wagner, N.J., 2009. Thixotropy. Advances in Colloid and Interface Science 2171 147-148, 214-227.

2172 
2173 Mikkelsen, L.H., 2001. The shear sensitivity of activated sludge: relations to filterability,

2174 rheology and surface chemistry. Colloids and Surfaces A: Physicochemical and

2175 Engineering Aspects 182 (1-3), 1-14

2176

2177 Moeller, G., Torres, L.G., 1997. Rheological characterization of primary and secondary 2178 sludges treated by both aerobic and anaerobic digestion. Bioresource Technology 61(3) $2179 \quad 207-211$.

2180

2181 Moller, P.C.F., Mewis, J., Bonn, D., 2006. Yield stress and thixotropy: on the difficulty of 2182 measuring yield stresses in practice. Soft Matter 2(4), 274-283.

2183

2184 Moreau, A.A., Ratkovich, N., Nopens, I., Van der Graff, J.H. J.M., 2009. The 2185 (in)significance of apparent viscosity in full-scale municipal membrane bioreactors. Journal 2186 of Membrane Science 340(1-2), 249-256.

2187

2188 Mori, M., Isaac, J., Seyssiecq, I., Roche, N., 2008. Effect of measuring geometries and of 2189 exocellular polymeric substances on the rheological behaviour of sewage sludge. Chemical 2190 Engineering Research and Design 86(6), 554-559.

2191

2192 Mori, M., Seyssiecq, I., Roche, N., 2006. Rheological measurements of sewage sludge for 2193 various solids concentrations and geometry. Process Biochemistry 41(7), 1656-1662. 2194 
2195 Mu, Y., Chen, XH., Yu, HQ., 2006. Rheological and fractal characteristics of granular

2196 sludge in an upflow anaerobic reactor. Water Research 40(19), 3596-3602.

2197

$2198 \mathrm{Mu}, \mathrm{Y} ., \mathrm{Yu}, \mathrm{HQ} .$, Wang, Y., 2007. A kinetic approach to anaerobic hydrogen-producing 2199 process. Water Research 41(5), 1152-1160.

2200

2201 Nguyen, T.P., Boger, D.V., 1992. Measuring the flow properties of yield stress fluids. 2202 Annual Review of Fluid Mechanics 24, 47-88.

2203

2204 Nguyen, T.P., Hankins, N.P., Hilal, N., 2007a. A comparative study of the flocculation 2205 behaviour and final properties of synthetic and activated sludge in wastewater treatment. 2206 Desalination 204 (1-3), 277-295.

2207

2208 Nguyen, T.P., Hankins, N.P., Hilal, N., 2007b. Effect of chemical composition on the 2209 flocculation dynamics of latex-based synthetic activated sludge. Journal of Hazardous 2210 Materials 139 (2), 265-274.

2211

2212 Ogawa, A., Yamada, H., Matsuda, S., Okajima, K., 1997. Viscosity equation for 2213 concentrated suspensions of charged colloidal particles. Journal of Rheology 41(3), 7692214785.

2215

2216 Örmeci, B., 2007. Optimization of a full-scale dewatering operation based on the 2217 rheological characteristics of wastewater sludge. Water Research 41(6), 1243-1252. 
2219 Örmeci, B., Abu-Orf, M., 2005. Protocol to measure network strength of sludges and its 2220 implications for dewatering. Journal of Environmental Engineering 131(1), 80-85 .

2221

2222 Papanastasiou, T.C., 1987. Flows of materials with yield. Journal of Rheology 31(5), 3852223404.

2224

2225 Paredes, J., Shahidzadeh-Bonn, N., Bonn, D., 2011. Shear banding in thixotropic and 2226 normal emulsions. Journal of Physics: Condensed Matter 23(28), 284116.

2228 Pevere, A., Guibaud, G., Goin, E., Van Hullebusch, E., Lens, P., 2009. Effects of physico2229 chemical factors on the viscosity evolution of anaerobic granular sludge. Biochemical 2230 Engineering Journal 43, 231-238.

2231

2232 Pevere, A., Guibaud, G., Van Hullebusch, E., Lens, P., Baudu, M., 2006. Viscosity 2233 evolution of anaerobic granular sludge. Biochemical Engineering Journal, 27(3), 315-322.

2235 Pevere, A., Guibaud, G., Van Hullebusch, E., Boughzala, W., Lens, P., 2007. Effect of Na 2236 and $\mathrm{Ca}^{2+}$ on the aggregation properties of sieved anaerobic granular sludge. Colloids and 2237 Surfaces A: Physicochemical and Engineering Aspects 306(1-3), 142-149. 
2239 Pham, T.T.H., Brar, S.K., Tyagi, R.D., Surampalli, R.Y., 2009. Ultrasonication of 2240 wastewater sludge - Consequences on biodegradability and flowability. Journal of 2241 Hazardous Materials 163(2-3), 891-898.

2242

2243 Pham, T.T.H., Brar, S.K., Tyagi, R.D., Surampalli, R.Y., 2010. Influence of ultrasonication 2244 and Fenton oxidation pre-treatment on rheological characteristics of wastewater sludge. 2245 Ultrasonics Sonochemistry 17(1), 38-45.

2247 Plósz , B.G., Weiss, M., Printemps, C., Essemiani, K., Meinhold, J., 2007. One2248 dimensional modelling of the secondary clarifier-factors affecting simulation in the 2249 clarification zone and the assessment of the thickening flow dependence. Water Research $2250 \quad 41(15), 3359-3371$.

2251

2252 Poitou, A., Racineux, G., Burlion, N., 1997. Identification and measurement of pastes 2253 rheological properties - Effects of water dissociation. Water Science and Technology $225436(11), 19-26$.

2255

2256 Pollice, A., Giodarno, C., Laera, G., Saturno, D., Mininni, G., 2007. Physical 2257 characteristics of the sludge in a complete retention membrane bioreactor. Water Research 2258 41(8), 1832-1840. 
2260 Pollice, A., Laera, G., Saturno, D., Giodarno, C., 2008. Effects of sludge retention time on

2261 the performance of a membrane bioreactor treating municipal sewage. Journal of

2262 Membrane Science 317(1-2), 65-70.

2263

2264 Popovic, M., Robinson, C.W., 1984. Estimation of some important design parameters for 2265 non-Newtonian liquids in pnermatically-agitated fermenters. Proceedings of the 34th 2266 Canadian Chemical Engineering Congress, Québec, Canada.

2268 Ratkovich, N., Horn, W., Helmus, F.P., Rosenberger, S., Naessens, W., Nopens, I., Bentzen, 2269 T.R., 2013. Activated Sludge Rheology: A crtitcal review on data collection and modelling. 2270 Water Research 47,463-482.

2271

2272 Riley, D.W., Forster, C.F., 2001. The physico-chemical characteristics of thermophilic 2273 aerobic sludges. Journal of Chemical Technology \& Biotechnology 76(8), 862-866.

2275 Rosenberger, S., Kubin, K., Kraume, M., 2002. Rheology of activated sludge in membrane 2276 bioreactors. Engineering in Life Sciences 2(9), 269-275.

2278 Ruiz-Hernando, M., Labanda, J., Llorens, J., 2010. Effect of ultrasonic waves on the 2279 rheological features of secondary sludge. Biochemical Engineering Journal 52(2-3), 1312280136.

2281 
2282 Saffarian, M.R., Hamedi, M.H., Shams, M., 2011. Numerical simulation of a secondary

2283 clarifier in a sewage treatment plant using modified Bingham model. Canadian Journal of

2284 Civil Engineering 38(1), 11-22.

2285

2286 Sanin, D.F., 2002. Effect of solution physical chemistry on the rheological properties of 2287 activated sludge. Water SA, 28(2), 207-212.

2288

2289 Seviour, T., Pijuan, M., Nicholson, T., Keller, J., Yuan, Z., 2009a. Understanding the 2290 properties of aerobic sludge granules as hydrogels. Biotechnology and Bioengineering 2291 102(5), 1483-1493.

2292

2293 Seviour, T., Pijuan, M., Nicholson, T., Keller, J., Yuan, Z., 2009b. Gel-forming 2294 exopolysaccharides explain basic differences between structures of aerobic sludge granules 2295 and floccular sludges. Water Research 43(18), 4469-4478.

2296

2297 Seyssiecq, I., Ferrasse, J.H., Roche, N., 2003. State-of-the-art: rheological characterisation 2298 of wastewater treatment sludge. Biochemical Engineering Journal 16(1), 41-56. 2299

2300 Seyssiecq, I., Marrot, B., Djerroud, D., Roche, N., 2008. In situ triphasic rheological 2301 characterisation of activated sludge in an aerated bioreactor. Chemical Engineering Journal $2302142(1), 40-47$.

2303 
2304 Sirman, J.M., 1960. Determination of flow parameters of waste sludge. Water and Sewage 2305 Works, 107, 417.

2306

2307 Slatter, P.T., 1997. The rheological characterisation of sludges. Water Science \& 2308 Technology 36(11), 9-18.

2309

2310 Slatter, P.T., 2001. Sludge pipeline design. Water Science and Technology 44(10), 1152311120.

2312

2313 Slatter, P.T., 2003. Pipeline transport of thickened sludges. Water 21, 56-57.

2314

2315 Slatter, P.T., 2004. The hydraulic transportation of thickened sludges. WaterSA 30(5), 66$2316 \quad 68$.

2317

2318 Slatter, P.T., 2008. Pipe flow of highly concentrated sludge. Journal Environment Science 2319 and Health Part A 43(13), 1516-1520.

2320

2321 Slatter, P.T., 2011. The engineering hydrodynamics of viscoplastic suspensions. Journal of 2322 Particulate Science and Technology 29 (2), 139-150.

2323

2324 Slatter, P.T., Peterson, F.W., Moodie, L., 1998. Rheological characterisation of mineral 2325 slurries using balanced beam tube viscometry. The Journal of the South African Institite of 2326 Mining and Metallurgy 98(4), 165-170. 
2328 Slatter, P.T., Moodie, L. Petersen, F.W., 1996. Recent developments in balanced beam

2329 tube viscometer. British Hydromechanics Research Group 13th International Conference on

2330 Slurry Handling and Pipeline Transport: Hydrotransport 13, Johannesburg.

2332 Sozanski, M.M., Kempa, E.S., Grocholski, K., Bien, J., 1997. The rheological experiment 2333 in sludge properties research. Water Science \& Technology 36(11), 69-78.

2335 Spinosa, L., Lotito, V., 2003. A simple method for evaluating sludge yield stress. Advances 2336 in Environmental Research 7(3), 655-659.

2338 Sutapa, I.D.A., Prost, C., 1996. Physico-chemical properties and settleability of activated 2339 sludge in relation with oxygen transfer and biofloculation. Institut National Polytechnique 2340 de Lorraine, France.

2342 Sybililski, D., 2011. Zero-shear viscosity of bituminous binder and its relation to 2343 bituminous mixture's rutting resistance. Transport Research Record, 1535, 15-21.

2345 Su, K.Z., and Yu., HQ., 2005. Formation and characterization of aerobic granules in a 2346 sequencing batch reactor treating soybean-processing wastewater. Environmental Science 2347 and Technology. 39, 2818-2827. 
2349 Terashima, M., Goel, R., Komatsu, K., Yasui, H., Takahashi, H., Li, Y.Y., Noke, T., 2009.

2350 CFD simulation of mixing in anaerobic digesters. Bioresource Technology 100 (7), 2228-

23512233.

2352

2353 Tixier, N., Guibaud, G., Baudu, M., 2003a. Effect of pH and ionic environment changes on 2354 interparticle interactions affecting activated sludge flocs: A rheological approach. 2355 Environmental Technology 24(8), 971-978.

2357 Tixier, N., Guibaud, G., Baudu, M., 2003b. Determination of some rheological parameters 2358 for the characterization of activated sludge. Bioresource Technology 90(2), 215-220.

2360 Toorman, E.A., 1997. Modelling of the thixotropic behaviour of dense cohesive sediment 2361 suspensions. Rheologica Acta 36(1), 56-65.

2363 Valioulis, I., 1980. Relationship between settling, dewatering and rheological properties of 2364 activated sludge. Master of Science Thesis, Cornell University, New-York, USA.

2365

2366 Van Kaam, R., Anne-Archard, D., Gaubert, M.A., Albasi, C., 2008. Rheological 2367 characterization of mixed liquor in a submerged membrane bioreactor: Interest for process 2368 management. Journal of Membrane Science 317(1-2), 26-33.

2370 Van Wazer, J.R., 1963. Viscosity and flow measurement: A laboratory handbook of 2371 rheology, New York, Interscience Publisher. 
2373 Verma, M., Brar, S., Tyagi, R., Surampalli, R., Valéro, J., 2006. Dissolved oxygen as 2374 principal parameter for conidia production of biocontrol fungi Trichoderma viride in non2375 Newtonian wastewater. Journal of Industrial Microbiology \& Biotechnology 33, 941-952. 2376

2377 Verma, M., Brar, S.K., Riopel, A.R., Tyagi, R.D., Surampalli, R.Y., 2007a. Pretreatment of 2378 wastewater sludge biodegradability and rheology study. Environmental Technology 28(3), $2379 \quad 273-284$.

2381 Verma, M., Brar, S.K., Tyagi, R.D., Sahai, V., Prévost, D., Valéro, J., Surampalli, R., 2382 2007b. Bench-scale fermentation of Trichoderma viride on wastewater sludge: Rheology, 2383 lytic enzymes and biocontrol activity. Enzyme and Microbial Technology 41(6-7), 7642384771.

2385

2386 Wang, Y., Dieudé-Fauvel, E., Dentel, S.K., 2011. Physical characteristics of conditioned 2387 anaerobic digested sludge - A fractal, transient and dynamic rheological viewpoint. Journal 2388 of Environmental Sciences 23(8), 1266-1273.

2390 Wang, Y.L., Dentel, S.K., 2011. The effect of polymer doses and extended mixing intensity 2391 on the geometric and rheological characteristics of conditioned anaerobic digested sludge 2392 (ADS). Chemical Engineering Journal 166(3), 850-858. 
2394 Ward, O.P., Burd, H., 2004. Treatment of sewage sludge. Lystek International Inc., United 2395 States.

2396

2397 Weiss, M., Plósz, B.G., Essemiani, K., Meinhold, J., 2007. Suction-lift sludge removal and 2398 non-Newtonian flow behaviour in circular secondary clarifiers: Numerical modelling and 2399 measurements. Chemical Engineering Journal, 132(1-3), 241-255.

2401 Wilen, B.M., Jin, B., Lant, P., 2003. The influence of key chemical constituents in activated 2402 sludge on surface and flocculating properties. Water Research 37(9), 2127-2139.

2404 Wu, X.H., Wang, F., Sun, D.X., Yang, W.H., 2011. Rheology and flow characteristic of 2405 urban untreated sewage for cooling and heating source. Experimental Thermal and Fluid 2406 Science 35(4), 612-617.

2408 Yang, F., Bick, A., Shandalov, S., Brenner, A., Oron, G., 2009. Yield stress and rheological 2409 characteristics of activated sludge in an airlift membrane bioreactor. Journal of Membrane 2410 Science 334(1-2), 83-90.

2412 Zhou, Z., Scales, P.J., Boger, D.V., 2001.Chemical and physical control of the rheology of 2413 concentrated metal oxide suspensions. Chemical Engineering Science 56(9), 2901-2920. 2414 